OPEN ACCESS

Edited by: Doug LaRowe, University of Southern California, United States

Reviewed by: Julie L. Meyer, University of Florida, United States Jason B. Sylvan

Texas A\&M University, United States

${ }^{*}$ Correspondence: Huaiyang Zhou zhouhy@tongji.edu.cn

Specialty section This article was submitted to Extreme Microbiology, a section of the journal Frontiers in Microbiology

Received: 15 March 2017 Accepted: 06 July 2017

Published: 21 July 2017

Citation:

Li J, Cui J, Yang Q, Cui G, Wei B, Wu Z, Wang $Y$ and Zhou $H$ (2017)

Oxidative Weathering and Microbial Diversity of an Inactive Seafloor Hydrothermal Sulfide Chimney.

Front. Microbiol. 8:1378. doi: 10.3389/fmicb.2017.01378

\section{Oxidative Weathering and Microbial Diversity of an Inactive Seafloor Hydrothermal Sulfide Chimney}

\author{
Jiangtao Li', Jiamei Cui ${ }^{1}$, Qunhui Yang ${ }^{1}$, Guojie Cui ${ }^{2}$, Bingbing Wei ${ }^{1}$, Zijun Wu ${ }^{1}$, \\ Yong Wang ${ }^{2}$ and Huaiyang Zhou ${ }^{1 *}$ \\ ' State Key Laboratory of Marine Geology, Tongji University, Shanghai, China, ${ }^{2}$ Institute of Deep-Sea Science and \\ Engineering, Chinese Academy of Sciences, Sanya, China
}

When its hydrothermal supply ceases, hydrothermal sulfide chimneys become inactive and commonly experience oxidative weathering on the seafloor. However, little is known about the oxidative weathering of inactive sulfide chimneys, nor about associated microbial community structures and their succession during this weathering process. In this work, an inactive sulfide chimney and a young chimney in the early sulfate stage of formation were collected from the Main Endeavor Field of the Juan de Fuca Ridge. To assess oxidative weathering, the ultrastructures of secondary alteration products accumulating on the chimney surface were examined and the presence of possible Fe-oxidizing bacteria (FeOB) was investigated. The results of ultrastructure observation revealed that FeOB-associated ultrastructures with indicative morphologies were abundantly present. Iron oxidizers primarily consisted of members closely related to Gallionella spp. and Mariprofundus spp., indicating Fe-oxidizing species likely promote the oxidative weathering of inactive sulfide chimneys. Abiotic accumulation of Fe-rich substances further indicates that oxidative weathering is a complex, dynamic process, alternately controlled by FeOB and by abiotic oxidization. Although hydrothermal fluid flow had ceased, inactive chimneys still accommodate an abundant and diverse microbiome whose microbial composition and metabolic potential dramatically differ from their counterparts at active vents. Bacterial lineages within current inactive chimney are dominated by members of $\alpha-, \delta$-, and $\gamma$-Proteobacteria and they are deduced to be closely involved in a diverse set of geochemical processes including iron oxidation, nitrogen fixation, ammonia oxidation and denitrification. At last, by examining microbial communities within hydrothermal chimneys at different formation stages, a general microbial community succession can be deduced from early formation stages of a sulfate chimney to actively mature sulfide structures, and then to the final inactive altered sulfide chimney. Our findings provide valuable insights into the microbe-involved oxidative weathering process and into microbial succession occurring at inactive hydrothermal sulfide chimney after high-temperature hydrothermal fluids have ceased venting.

Keywords: Fe-oxidizing bacteria, oxidative weathering, biomineralization, inactive hydrothermal chimney, microbial diversity, microbial succession 


\section{INTRODUCTION}

Hydrothermal sulfide chimneys, typical products of seafloor hydrothermal activity, encompass a variety of complex and dynamic environments where hot, reductive hydrothermal fluid interacts with cold, oxygenated seawater. As one of the most productive ecosystems on Earth (Polz and Cavanaugh, 1995), active sulfide chimneys accommodate numerous unique microbial populations that obtain primary metabolic energy via chemosynthesis using a series of reactions made possible by the presence of intense chemical disequilibria between hydrothermal fluid and seawater. Since the discovery of seafloor hydrothermal vents (Corliss et al., 1979), many surveys have been performed to investigate microbial communities in active hydrothermal vent structures (Takai and Horikoshi, 1999; Hoek et al., 2003; Brazelton et al., 2006; Zhou et al., 2009; Anderson et al., 2015). Several recent analyses have further suggested that microbial community composition and distribution regularly shift in spatial distribution across active chimney walls in response to variable venting dynamics (Schrenk et al., 2003; Kormas et al., 2006; Li et al., 2014). When hydrothermal venting activity ceases, active sulfide chimneys no longer accumulate new sulfide deposits, and oxidative weathering becomes the dominant process. The steep thermal and chemical gradients that existed within active chimneys disappear, and a corresponding change of biotopes occurs (Erickson et al., 2009). A couple of studies suggest that microbial populations in inactive chimneys are remarkably distinct from those of actively venting structures, and that their biomass, diversity and activities are greater than those associated with active chimneys (Suzuki et al., 2004; Kato et al., 2010). Recently, Sylvan et al. (2012) revealed that a clear shift occurs from the dominant $\varepsilon$-Proteobacteria and Aquificae in active sulfides to bacterial communities dominated by $\alpha-, \beta-, \gamma-, \delta$-Proteobacteria and Bacteroidetes in inactive hydrothermal sulfides, indicating that inactive chimneys are remarkably distinct microbial habitats. However, compared with numerous explorations of active hydrothermal structures, there have been few studies focusing on inactive chimneys and the process of microbial succession after active venting ceases. In addition, although it has been suggested that minerals of inactive chimneys serve as critical energy sources to support the metabolic growth of various chemolithoautotrophs (McCollom, 2000; Edwards et al., 2003a), little is known about the extent to which microbial communities associated with quiescent chimneys continue to utilize those energy sources.

After cessation of hydrothermal venting, inactive chimneys continuously interact with seawater under low-temperature conditions, resulting in the oxidative weathering and alteration of various metal sulfides. Earlier studies revealed that mineraloxidizing bacteria directly use solid sulfide minerals as metabolic substrates and play a prominent role in the weathering of hydrothermal sulfide deposits (Wirsen et al., 1993; Eberhard et al., 1995; Edwards et al., 2003b). Textural observations provide unequivocal evidence that alteration and weathering products, i.e., $\mathrm{Fe}$ oxides, are mainly attributed to the biomineralization of autotrophic $\mathrm{Fe}$-oxidizing bacteria (FeOB). However, microbiological evidence of the existence of $\mathrm{Fe}$ oxidizers is lacking (Edwards et al., 2003b). Fe-rich ultrastructures with characterized morphologies such as twisted stalks, indicative of certain known $\mathrm{FeOB}$ groups, can be produced by two taxonomically distinct species, raising the question as to what types of $\mathrm{FeOB}$ are present and contribute to oxidative weathering near hydrothermal vents (Kato et al., 2009; Li et al., 2012).

In the present study, an inactive sulfide chimney was collected from the Main Endeavor Field (MEF) of the Juan de Fuca Ridge (JDF) (Supplementary Figure S1). Yellow to brown alteration products had accumulated on the surfaces of this inactive chimney, indicating the occurrence of oxidative weathering of sulfide minerals. Mineral compositions, total organic carbon (TOC), and microbial community structures were determined at different spatial positions on this inactive sulfide chimney. Moreover, ultrastructures of surface-weathered products were also described to characterize microbial contributions during oxidative weathering. In addition, a young sulfate chimney, representing the primary stage of chimney formation, was collected from MEF and analyzed to identify the microbial inhabitants of this young chimney. Here, we present an examination of the oxidative weathering of an inactive sulfide chimney, we report correlations between Fe-oxidizing bacterial taxa and the products of alteration reactions, and we characterize microbial succession of hydrothermal chimneys at different stages.

\section{MATERIALS AND METHODS}

\section{Sampling and Description of Samples}

An inactive sulfide chimney and a young active sulfate chimney were collected from the MEF of the JDF during the AT18-08 cruise of the R/V Atlantis with the ROV Jason II (dive number J2-577) between July 19 and August 1, 2011 (Supplementary Figure S1). The inactive sulfide chimney, referred to as MilliQ S10, was sampled from the Milli-Q site, and the young sulfate chimney, CAP, was obtained from the Dudley site (Supplementary Figure S1). Milli-Q S10 was approximately $1 \mathrm{~m}$ long with variable diameters from 15 to $50 \mathrm{~cm}$ and displayed several flange structures (Supplementary Figure S2). Generally, this chimney was dark overall but commonly coated with yellow and brown patches on its top portion (Figure 1a). There was no visible emission of fluid or colonization by living hydrothermal fauna. However, considerable numbers of dead tubeworms were attached to the surfaces of the Milli-Q S10 chimney (Supplementary Figure S2), supporting the inactivity of this chimney (Haymon et al., 2008). During the sampling by ROV Jason II, several small secondary structures were broken from the Milli-Q S10 chimney. One of these structures, referred to as Milli-Q S10-4, was cone shaped, with dimensions of approximately $20 \mathrm{~cm}$ in height, $15 \mathrm{~cm}$ in diameter at bottom and $10 \mathrm{~cm}$ in diameter on top (Figure $\mathbf{1 b}$ ), exhibiting a thin reddish layer on the surface. Unlike Milli-Q S10, its surface was smooth, without any indications of tubeworms or other invertebrates. The active CAP chimney was collected from the top of a sulfide mound (Supplementary Figure S2). In 2006, cone-shaped cap equipment was placed on one active vent to 

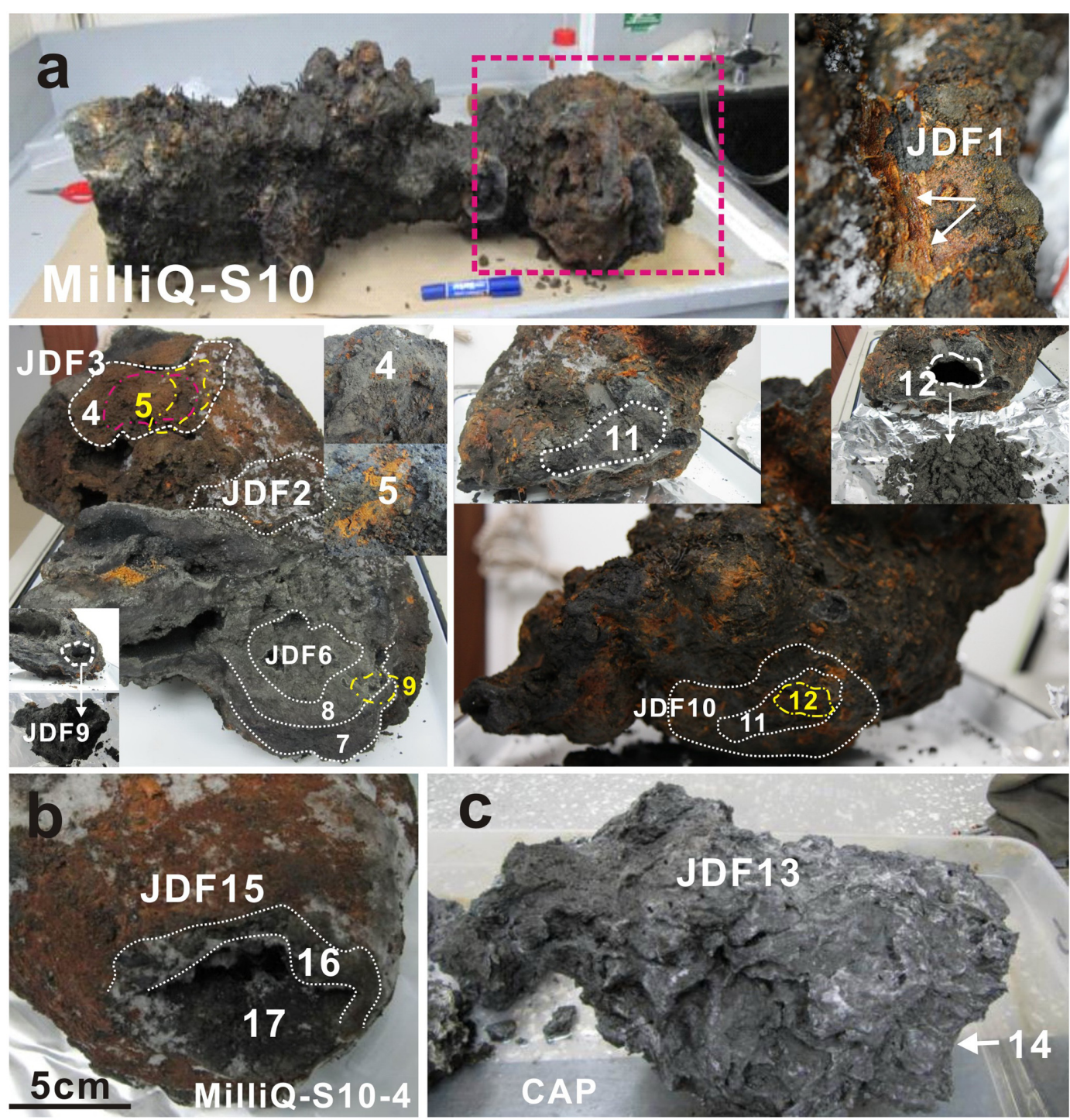

FIGURE 1 | Positions of subsampling from the inactive sulfide chimney (Milli-Q S10 and Milli-Q S10-4) and young sulfate chimney (CAP). (a) Milli-Q S10 inactive sulfide chimney. Red rectangle indicates the analyzed segment in present study. JDF1 was stripped from yellow surficial chimney walls (shown by arrows). Both JDF2 and JDF3 were subsampled from the exterior walls but different locations. JDF4 was taken from the position just under JDF3, while JDF5 was obtained below JDF4 and it was a thin layer of microbial mats. JDF6-JDF8 were stripped step by step from the exterior to the interior around a fluid conduit. JDF9 was subsampled from the inner part of another conduit closely next to JDF6 (shown in figure). JDF10-JDF12 were also obtained layer by layer around one conduit at another side of the chimney. (b) Milli-Q S10-4 structure broken from the inactive chimney and spatial positions of subsampling JDF15-JDF17. JDF15 was stripped from the yellow outer walls, JDF16 was derived from the middle position, and JDF17 was subsampled from a site adjacent to the central channel. (c) Young active sulfate chimney CAP. JDF13 was collected from the exterior wall and JDF14 was taken from the middle part of chimney wall.

monitor the formation of the chimney and microbial metabolic succession (Wang F. et al., 2009). After nearly 5 years, the initial small chimney had developed into a sulfide mound and our cap equipment was completely embedded within it. At the time of sampling, a newly formed sulfate chimney with a height of approximately $1.2 \mathrm{~m}$ was growing on the surface of the sulfide mound (Supplementary Figure S2). These chimneys were stored at $-80^{\circ} \mathrm{C}$ immediately after shipboard recovery and preserved on dry ice during transportation to our lab, where they were stored at $-80^{\circ} \mathrm{C}$ until further analyses.

\section{Subsampling from the Inactive Sulfide Chimney and Young Active Sulfate Chimney}

The top section of the inactive sulfide chimney Milli-Q S10, which was spotted with yellow and brown secondary products and attached dead tubeworms (Supplementary Figure S2), was analyzed. Milli-Q S10 was an irregular chimney in which multiple, interconnected conduits of hydrothermal fluid were present. A total of 12 subsamples were collected from the exterior surfaces to the interior fluid conduits across the chimney walls, 
according to spatial positions within the chimney (Figure 1a). Four subsamples (JDF1-JDF3, JDF10) were collected from the exterior walls at different positions with different degrees of alteration or weathering, and three subsamples (JDF6, JDF9, and JDF12) were obtained from the interior walls close to the fluid conduits. For exterior samples, surface scrapings penetrated on average $\sim 2-3 \mathrm{~mm}$. For interior samples, scrapings were taken $\sim 0-15 \mathrm{~mm}$ from the chimney exterior. Five other subsamples (JDF4, JDF5, JDF7, JDF8, and JDF11) were collected from the middle regions between the surfaces and interior conduitings. JDF5 consisted of a thin yellow layer considered as microbial mats which was yellow, soft and enriched in organic components (Figure 1a). Details of subsampling from Milli-Q S10 are shown in Figure 1a. By contrast, another inactive sulfide structure section, Milli-Q S10-4, which was broken from the Milli-Q S10 chimney, contained a single central conduit (Figure 1b). As shown in Figure 1b, three subsamples from the exterior surface ( $\sim 2-3 \mathrm{~mm}$ ) (JDF15), middle layer $(\sim 10-20 \mathrm{~mm}$ from the surface) (JDF16) and interior wall ( $\sim 0-10 \mathrm{~mm}$ from the exterior) (JDF17) were taken. The young sulfate chimney CAP was still active (Supplementary Figure S2), and many small pores and irregular channels were noted within its loose and fragile chimney walls (Figure 1c). Only two subsamples were collected from the outer (JDF13) and middle ( $~ 5-8 \mathrm{~cm}$ from the surface) (JDF14) walls of this active chimney.

In addition, subsamples were collected for ultrastructure observation, including from the yellow weathered surficial chimney walls (WSS1, WSS3, and WSS15), microbial mats (JDF15) and mineralized tubes of dead tubeworms (T1, T2-L/S, T3-1) attached to the surficial walls of the inactive chimney.

\section{Mineralogical Analysis}

Subsamples for mineralogical analysis were dried at $50^{\circ} \mathrm{C}$ and thoroughly ground to fine powder $(\sim 0.074 \mathrm{~mm})$ using a mortar and pestle. X-ray diffraction (XRD) pattern analysis was performed using a Rint $2000 \mathrm{X}$-ray diffractometer $(\mathrm{Cu} \mathrm{K} \alpha$ radiation at $40 \mathrm{kV}$ and $30 \mathrm{~mA}$, scanning from 2 to $80^{\circ}$, scan velocity of $1^{\circ} 2 \theta / \mathrm{min}$ ). Diffraction angles (referred to as ' $2 \theta^{\prime}$ ) corresponding to the atomic structure unique to each mineral were measured.

Subsample JDF1 obtained from the outmost yellowish surfaces of the inactive chimney was also subjected to Fourier transform infrared spectroscopy (FT-IR) because of its poor crystallinity. The FT-IR analysis was run with a Nciolet 5700 spectrometer using the $\mathrm{KBr}$ pellet method. Finely ground samples, $\sim 1 \mathrm{mg}$, were mixed with $200 \mathrm{mg} \mathrm{KBr}$ (FTIR grade, Fluka) in a vibratory ball mixer for $20 \mathrm{~s}$. These mixtures were later pressed under a vacuum in a standard device at a pressure of $75 \mathrm{kN} \mathrm{cm}^{2}$ for $3 \mathrm{~min}$ to produce a transparent disk measuring approximately $1 \mathrm{~mm}$ in thickness and $13 \mathrm{~mm}$ in diameter. The spectral resolution was $4 \mathrm{~cm}^{-1}$, and the scanning range was from 600 to $4000 \mathrm{~cm}^{-1}$.

\section{Scanning Electron Microscopy (SEM)}

Small fragments were collected from the inactive chimney, freeze dried thoroughly, and sputter coated with gold for 23 min. All were examined with a Philips XL-30 SEM instrument equipped with an EDAX energy-dispersive X-ray spectrometer and the corresponding analytical software. Energy-dispersive $\mathrm{X}$-ray spectroscopy (EDS) was primarily qualitative in nature because of the irregular surface topography of the samples. The SEM was operated at $15 \mathrm{kV}$ with a working distance of $10 \mathrm{~mm}$ to ensure optimum imaging and minimize charging and sample damage.

\section{Analysis of Total Organic Carbon (TOC)}

Freeze-dried subsamples were homogenized with an agate mortar and pestle, then transferred into pre-weighed aluminum foil capsules, treated with $10 \%$ hydrochloric acid to remove carbonates, and dried overnight at $40-50^{\circ} \mathrm{C}$. TOC values in hydrothermal precipitates were quantified with a Vario E1III Elemental Analyzer interfaced with a Thermo Finnigan DELTA plus XL stable isotope ratio mass spectrometer. Analyses were normalized relative to an acetanilide standard. The concentrations of TOC were expressed as percent dry precipitates.

\section{DNA Extraction, Construction of Clone Libraries, Sequencing, and Phylogenetic Analyses}

DNA was extracted using an SDS-based extraction method with some modifications (Zhou et al., 1996). In brief, approximately 5-10 g of precipitate was mixed with $13.5 \mathrm{~mL}$ of DNA extraction buffer (100 mM Tris- $\mathrm{HCl}, 100 \mathrm{mM}$ sodium EDTA, $100 \mathrm{mM}$ sodium phosphate, $1.5 \mathrm{M} \mathrm{NaCl}, 1 \% \mathrm{CTAB}$ ) and $100 \mu \mathrm{L}$ of proteinase K (10 mg/mL, Sigma) in tubes via horizontal shaking at $225 \mathrm{rpm}$ for $30 \mathrm{~min}$ at $37^{\circ} \mathrm{C}$. After shaking, $1.5 \mathrm{~mL}$ of $20 \%(\mathrm{w} / \mathrm{v})$ SDS was added, and the samples were incubated in a $65^{\circ} \mathrm{C}$ water bath for $2 \mathrm{~h}$. The supernatants were collected after centrifugation at $6000 \times g$ for $10 \mathrm{~min}$ and transferred into $50 \mathrm{~mL}$ centrifuge tubes. The supernatants were mixed with an equal volume of chloroform isoamyl alcohol $(24: 1, \mathrm{v} / \mathrm{v})$. The aqueous phase was recovered by centrifugation and precipitated with 0.6 volumes of isopropanol for approximately $1 \mathrm{~h}$. Crude nucleic acids were obtained by centrifugation at $16,000 \times g$ for $20 \mathrm{~min}$ at room temperature, washed with $70 \%$ ethanol and resuspended in sterile deionized water. The crude nucleic acids were purified with the OMEGA EZNA $^{\text {TM }}$ Cycle-Pure Kit.

Two subsamples, JDF5 and JDF15, which were obtained from microbial mats and the outmost chimney wall, respectively, were used to detect FeOB-associated species using 16S rRNA gene clone libraries. The bacterial 16S rRNA gene was amplified using the primers 27F (5'-AGA GTT TGA TCC TGG CTC AG-3')/1492R (5'-GGT TAC CTT GTT ACG ACT T-3') which produced $\sim 1500$ bp products (Lane, 1991). The specific primers Zeta674F and 1492R were used to target members of $\zeta$-Proteobacteria (McBeth et al., 2011), and the specific primers 122F ( $5^{\prime}$-ATA TCG GAA CAT GTC CGG-3') and 998R (5'-CTC TGG AAA CTT CCT GAC-3') were used to capture bacteria closely related to Gallionella spp. (Wang J. et al., 2009). Amplification conditions were consistent with the conditions listed in the references noted above. The PCR products were purified with a gel-extraction kit (Omega, United States) according to the manufacturer's instructions. Purified 
PCR products were cloned into the pMD20-T vector (Takara, Japan) and transformed to competent Escherichia coli $\mathrm{DH} 5 \alpha$ cells (Takara, Japan). The correct-size inserts were screened with the vector-specific primers M13f (5'-GTA AAA CGA CGG CCA G-3') and M13r (5'-CAG GAA ACA GCT ATG AC-3'). Clones containing target $16 \mathrm{~S}$ rDNA were selected randomly for sequencing with an ABI PRISM 3730XL automated sequencer with vector-specific universal primers. Bacterial 16S rRNA gene sequences were checked for chimeras using Bellerophon (3.0) at http://greengenes.lbl.gov (Huber et al., 2004). The DOTUR program was used to cluster sequences into operational taxonomic units (OTUs) or phylotypes using a 97\% similarity cutoff (Schloss and Handelsman, 2005). All sequences and their close relatives obtained from GenBank and EMBL databases were aligned using ClustalX 2.0.1 (Larkin et al., 2007). FeOBrelated sequences obtained from near full-length 16S rRNA gene sequences and other specific taxonomic targets together with sequences of known FeOB species were used to construct phylogenetic trees under maximum-likelihood criteria using Mega 5.0 (Tamura et al., 2011). Bootstrap analysis was used to provide confidence estimates of tree topologies.

\section{Pyrosequencing and Analysis of 165 rRNA Sequence Amplicons}

DNA obtained from all 17 samples was quantified with a PicoGreen dsDNA Quantitation Kit (Life Technologies, Carlsbad, CA, United States). Total extracted DNA was used as template for PCR amplification of $16 \mathrm{~S}$ rRNA genes using primers designed with Barcrawl (Frank, 2009). Bacterial and archaeal 16S rRNA genes were amplified using the primers 27F (5'-AGA GTT TGA TCC TGG CTC AG-3')/533R (5' -TTA CCG CGG CTG CTG GCA C-3') containing 10-nucleotide barcodes and Arch344F (5'-ACG GGG YGC AGC AGG CGC GA-3')/Arch915R (5'-GTG CTC CCC CGC CAA TTC CT$\left.3^{\prime}\right)$ containing eight-nucleotide barcodes, respectively. The PCR reactions were first held in a thermocycler (Bio-Rad, Hercules, $\mathrm{CA}$, United States) at $94^{\circ} \mathrm{C}$ for $5 \mathrm{~min}$ to denature the DNA, followed by amplification for 25 cycles at $94^{\circ} \mathrm{C}$ for $50 \mathrm{~s}, 53^{\circ} \mathrm{C}$ for $50 \mathrm{~s}$, and $72^{\circ} \mathrm{C}$ for $50 \mathrm{~s}$. A final extension of $6 \mathrm{~min}$ at $72^{\circ} \mathrm{C}$ was added to ensure complete amplification. The PCR products purified with the TaKaRa Agarose Gel DNA Purification Kit (TaKaRa, Dalian, China) were quantified using a NanoDrop ND-1000 device (NanoDrop, Wilmington, DE, United States) and sent for 454/Roche GS-FLX Titanium platform at Majorbio Bio-Pharm Technology, Co., Ltd., Shanghai, China.

Downstream analysis of the pyrosequenced amplicon reads was performed using QIIME 1.9.1. Reads of low quality were filtered out by enforcing the following quality control criteria: (1) exclusion of reads with one or more ambiguous nucleotides, (2) exclusion of reads shorter than $200 \mathrm{bp}$, (3) exclusion of reads containing homopolymers of $6 \mathrm{bp}$ and above, and (4) exclusion of reads with an average flowgram score of 25 or below in a quality window of $50 \mathrm{bp}$. The quality-filtered reads were clustered into OTUs based on their sequence similarity, and a representative sequence from each OTU was selected using the longest picking method for downstream analysis. Taxonomy assignment was conducted using the RDP classifier against the SILVA 16S rRNA gene database (Version 119). Chimeric reads were identified and excluded using ChimeraSlayer in the QIIME package after alignment with PyNAST. Similarities among different microbial communities were determined using similarity matrices generated according to the phylogenetic distance between reads (Unifrac distance), and beta diversity of principal coordinates analysis (PCoA) was computed as components of the QIIME pipeline.

\section{Nucleotide Sequence Accession Numbers}

The 16S rRNA gene sequences of FeOB-associated lineages reported in this paper were deposited in GenBank under accession numbers KX023409 - KX023416. The pyrosequencing data for 16S rRNA genes were deposited in the GenBank Short Read Archive (SRA) under accession ID SRP073405.

\section{RESULTS}

\section{Mineral Compositions}

Mineral compositions and their abundances in different subsamples obtained from the inactive sulfide chimney and young active sulfate chimney were mainly determined using XRD analysis (Table 1). JDF1, scratched from the outmost yellowish surfaces of the inactive chimney, was subjected to XRD and FT-IR analyses because of its poor crystallinity. As shown in Figure 2A, the XRD pattern revealed that JDF1 mainly consisted of amorphous mineral assemblages and minor recognizable minerals including barite, pyrite, marcasite, and sulfur. The XRD pattern of amorphous mineral assemblages showed a broad hump at approximately $2 \theta$ of $32^{\circ}$ (d-spacing value $\sim 2.5 \AA$ ), and a very faint secondary peak at $2 \theta$ of $61^{\circ}$ (dspacing value $1.5 \AA$ ) (Figure $2 \mathrm{~A}$ ), closely similar to that of poorly crystallized iron oxyhydroxide and indicating the presence of two-line ferrihydrite (Boyd and Scott, 1999; Kennedy et al., 2003). FT-IR spectra also provided valuable information about Fe oxyhydroxides (Figure 2B). There were several prominent bands at $\sim 3380,1637,1399,1077$, and $984 \mathrm{~cm}^{-1}$. The band at $3380 \mathrm{~cm}^{-1}$ was assigned to the stretching vibration of $-\mathrm{OH}$ from surface $\mathrm{H}_{2} \mathrm{O}$ molecules or from an envelope of hydrogen-bonded surface - OH groups (Koji and Solomon, 1977; Gotić and Musić, 2007). The band at $1637 \mathrm{~cm}^{-1}$ was close to the position of $\mathrm{H}_{2} \mathrm{O}$ bending vibrations (Ryskin, 1974). The relatively weak peak, which appeared at $\sim 1399 \mathrm{~cm}^{-1}$, was assigned to $\mathrm{Fe}-\mathrm{OH}$ (Tuysuz et al., 2008), suggesting the presence of ferrihydrite. The bands at $\sim 980-1100 \mathrm{~cm}^{-1}$ could be attributed to the Si-O stretching vibration from the $\mathrm{SiO}_{4}$ tetrahedra with three or four bridge $\mathrm{O}$ atoms (Farmer, 1974; Vempati et al., 1990). Therefore, it was inferred from XRD and FT-IR analyses that JDF1, derived from yellowish substrates of the outermost surfaces of inactive chimney walls, mainly consisted of amorphous Fe oxyhydroxides. XRD recognizable minerals in JDF1 most likely came from the underlying mineral assemblages when we scratched the thin surfaces to sample (Figure 1). JDF5, identified as microbial mats (Figure 1a), was not analyzed because of its low masses. 


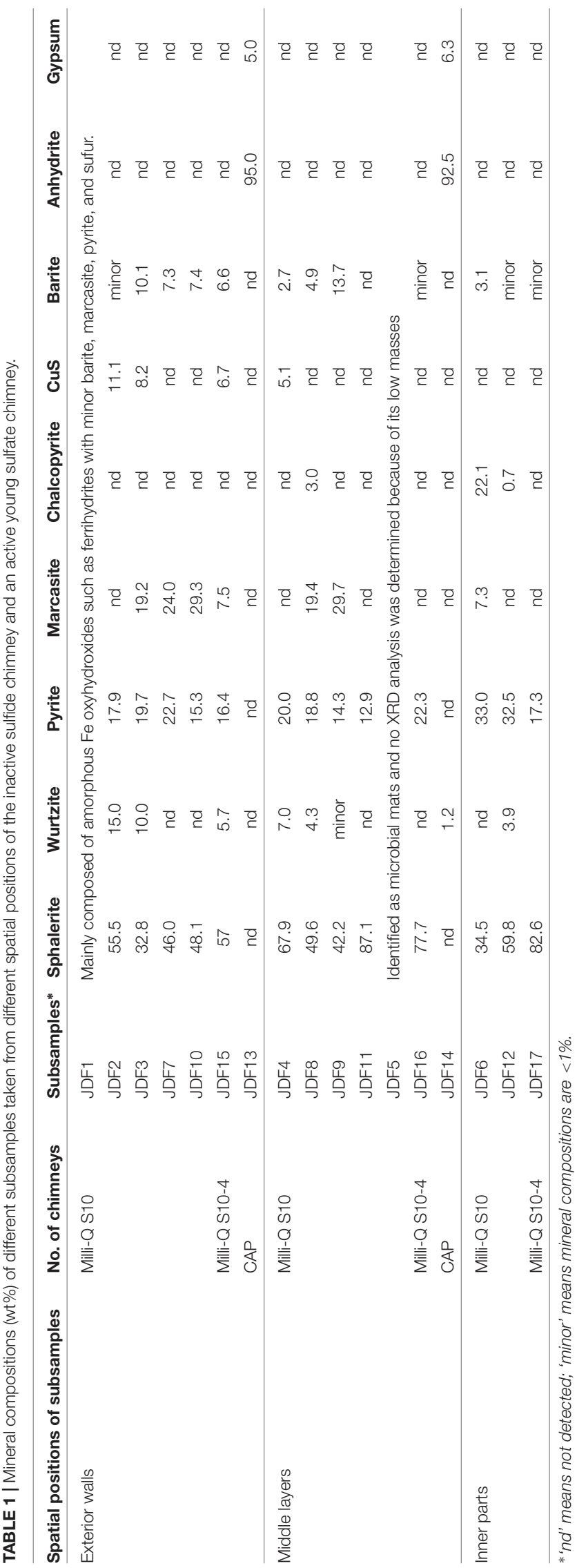

Except JDF1, other subsamples of Milli-Q S10 chimney and the S10-4 structure primarily consisted of various sulfide minerals such as sphalerite, wurtzite, pyrite, marcasite, and chalcopyrite (Table 1). Among them, sphalerite and pyrite were the most common and abundant mineral assemblages in all subsamples with contents of $32.8-82.6$ and $12.9-33.0 \mathrm{wt} \%$, respectively. Although contents of marcasite were sometimes high, varying from 7.3 to $29.7 \mathrm{wt} \%$, their distributions were limited. Wurtzite was generally less than $15 \mathrm{wt} \%$. Chalcopyrite was found only in locations closely adjacent to the central fluid channels such as JDF6, JDF8, and JDF12 and its abundance could be up to $22.1 \mathrm{wt} \%$. By contrast, the active young CAP chimney was distinct in mineral compositions from those of the inactive sulfide chimney and structure. Two subsamples of the CAP chimney predominantly consisted of anhydrite (92.5-95.0 wt\%) with minor gypsum (5.0-6.3 wt\%). Only a small amount of wurtzite (1.2 wt\%) was detected from JDF14.

\section{Total Organic Carbon (TOC) and $\delta^{13} \mathbf{C}_{\text {TOC }}$}

Total organic carbon concentrations varied from 0.04 to 1.91 wt\% (Figure 3). The highest TOC concentration (1.91 wt\%) was detected in the microbial mats of JDF5. Generally, TOC content decreased from the exterior positions to the inner positions across the inactive chimney walls (Figure 3). For example, within Milli-Q S10, TOC concentrations of several outer subsamples were commonly greater than $0.10 \mathrm{wt} \%$, especially in JDF2 and JDF3, whose TOC values reached $0.30 \mathrm{wt} \%$. In sharp contrast, two interior subsamples, JDF6 and JDF12, contained only 0.06 and $0.04 \mathrm{wt} \%$ TOC concentrations, respectively. The TOC concentrations of subsamples collected from the middle layers fell between those of the exterior and inner regions, with a range of $0.06-0.17 \mathrm{wt} \%$. A similar trend was present within the Milli-Q S10-4 structure (Figure 3). Two subsamples from the young CAP chimney had comparatively low TOC contents of approximately 0.05 and $0.06 \mathrm{wt} \%$.

The values of $\delta^{13} \mathrm{C}_{\text {TOC }}$ ranged from -18.82 to $-31.39 \%$ (Figure 3). Within the subsamples of Milli-Q S10, the lowest values of $\delta^{13} \mathrm{C}_{\mathrm{TOC}}$ were measured from two surficial subsamples, JDF2 and JDF3, with values of -31.39 and $-31.10 \%$, respectively. Other subsamples from middle and inner regions displayed similar ${ }^{13} \mathrm{C}_{\mathrm{TOC}}$ values varying between -27.02 and $-24.36 \%$ (Figure 3). For the subsamples of structure MilliQ S10-4, although the exterior JDF15 had $\delta^{13} \mathrm{C}_{\mathrm{TOC}}$ value of $-28.32 \%$ comparable to those of Milli-Q S10, the middle JDF16 and the inner JDF17 possessed the heaviest ${ }^{13} \mathrm{C}_{\mathrm{TOC}}$ with values of -18.82 and $-21.24 \%$, respectively, yielding a difference of $\sim 10 \%$ (Figure 3). JDF13 and JDF14, subsamples of the active CAP sulfate chimney, possessed $\delta^{13} \mathrm{C}_{\mathrm{TOC}}$ values of -24.84 and $-23.44 \%$, respectively.

\section{Morphological Observation and Description of Ultrastructures}

Numerous biogenic ultrastructures with distinctive morphologies were detected from the weathered surficial inactive chimney walls (Figure 4), the mineralized tubes of dead tubeworms (Figure 5), and microbial mats (Figure 5p 


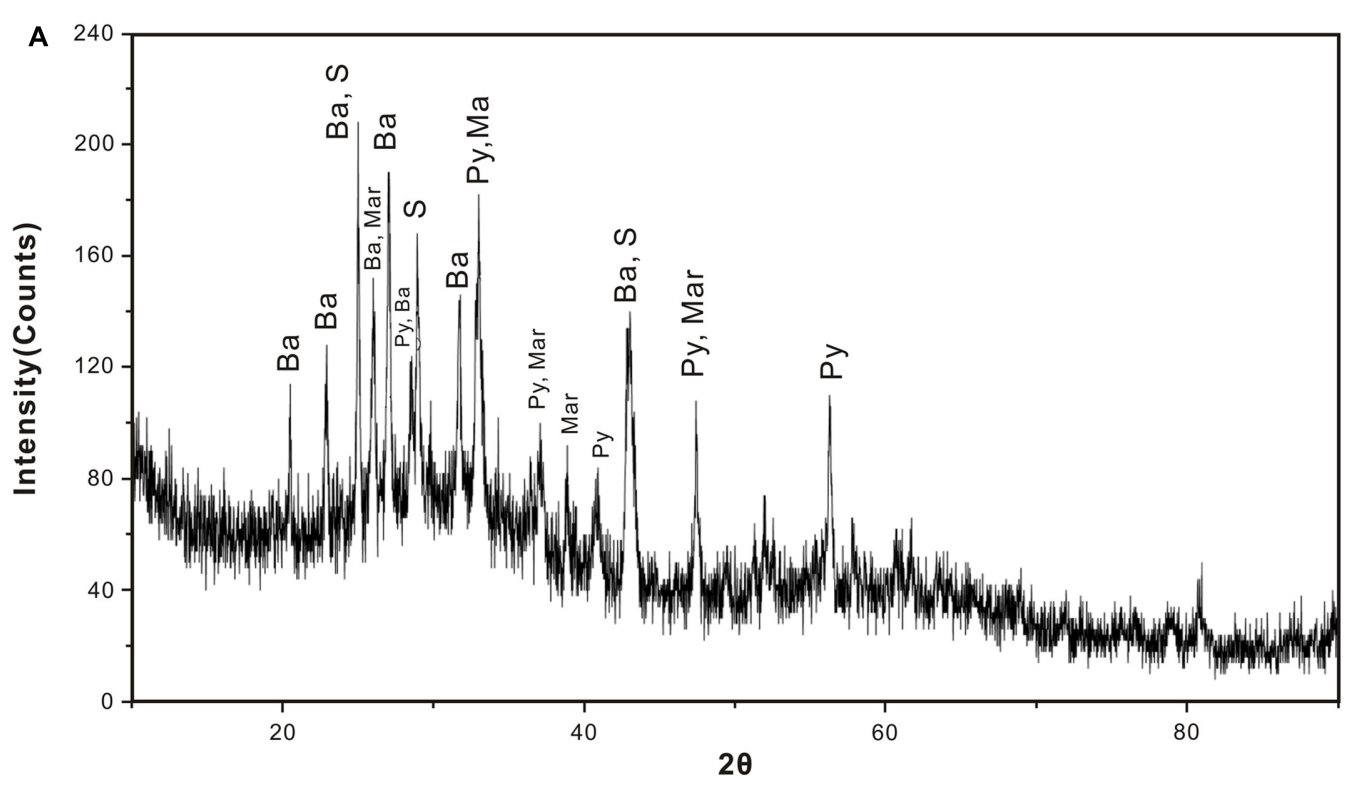

8

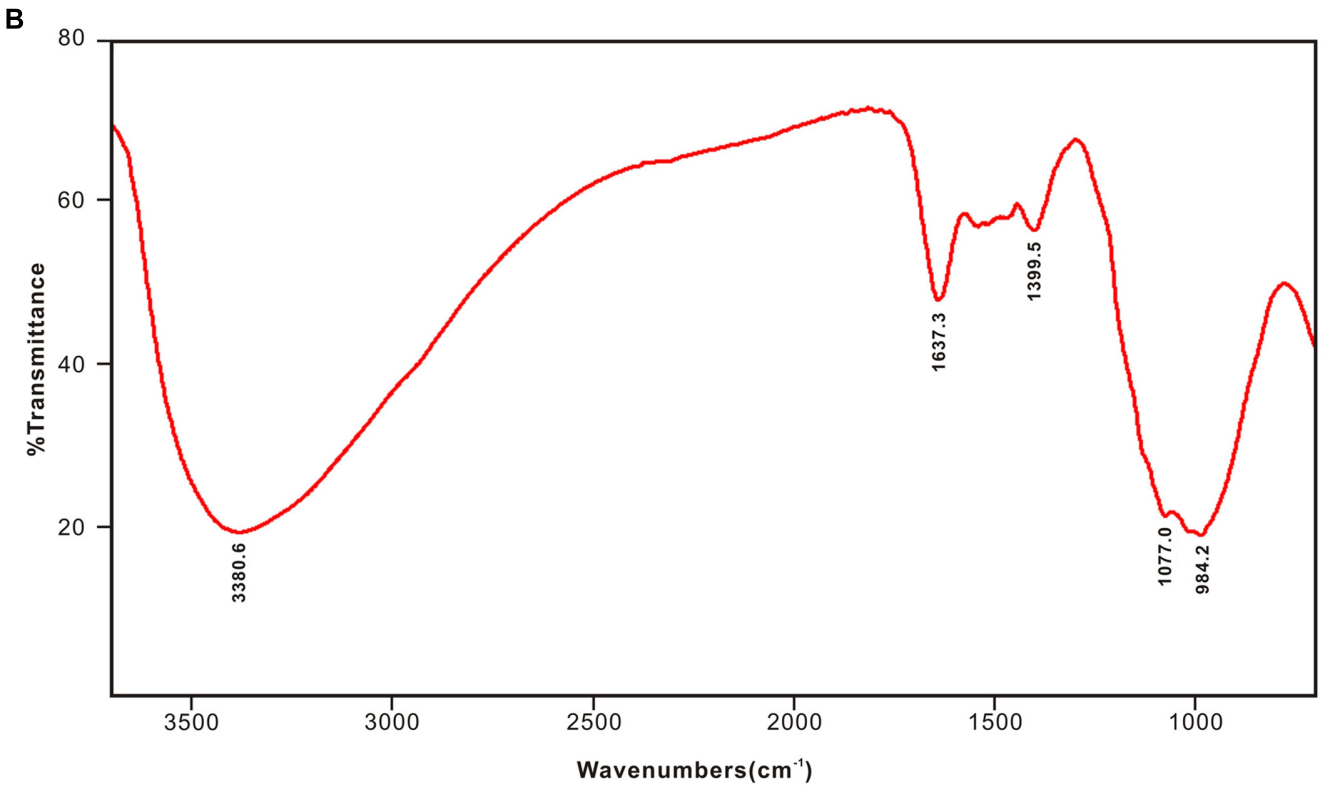

FIGURE 2 |XRD pattern (A) and FTIR spectra (B) of JDF1 scratched from the outermost yellowish surface of inactive hydrothermal chimney, indicating that subsamples JDF1 mainly consist of amorphous mineral assemblages. The faint secondary peak at $2 \theta$ of $61^{\circ}$ and weak absorption peak at $\sim 1399 \mathrm{~cm}^{-1}$ indicate the presence of poor crystalline two-line ferrihydrites. In (A), Ba: barite; S: sulfur; Py: pyrite; Mar: marcasite.

and Supplementary Figure S3). Among them, several kinds of distinguishable ultrastructures including twisted ribbonlike stalks (Figures 4a, 5p), branched stalks (Figures 4d,f and Supplementary Figure S3), straight tubular sheaths (Figures 4e, 5o) and irregular filaments (Figures 4b, 5m) were dominantly abundant and generally occurred in massive accumulations (Figures $\mathbf{4 a}, \mathbf{5 a}$ and Supplementary Figure S3). They commonly showed a hollow tubular aspect $0.5-2 \mu \mathrm{m}$ in diameter and up to tens of $\mu \mathrm{m}$ in length (Figures $4 \mathbf{a}-\mathbf{g}$ and Supplementary Figure S3). EDS analyses revealed that these ultrastructures were primarily composed of $\mathrm{Fe}$, commonly more than $50 \mathrm{wt} \%$, followed by variable amounts of $\mathrm{C}$ and $\mathrm{Si}$ (Figures 41,m). All these characteristics of morphologies and chemical components of ultrastructures (ribbon-like stalks, branched stalks, straight tubular sheaths, and irregular filaments) firmly demonstrated that they were typically biogenic FeOBassociated ultrastructures which are the exclusive products of several known Fe-oxidizing species such as Mariprofundus ferrooxydans, Gallionella ferruginea, and Leptothrix ochracea (Emerson et al., 2010; Chan et al., 2011; McAllister et al., 2011; Krepski et al., 2013). In most cases, these FeOB-associated ultrastructures had smooth surfaces (Figures $4 a-\mathbf{f}$ ) similar to the 


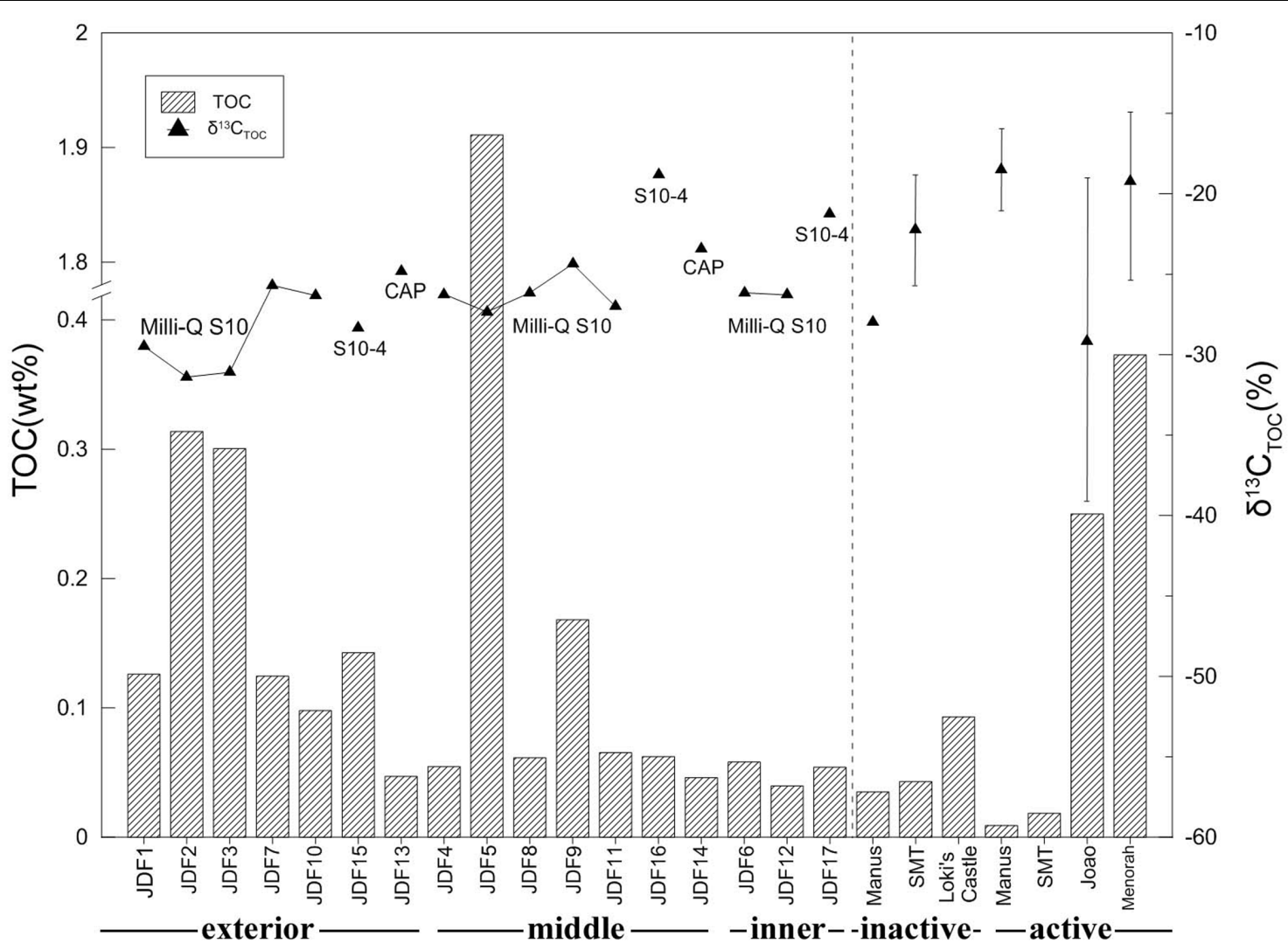

FIGURE 3 | Total organic carbon (TOC) and stable carbon isotopic ratio of subsamples collected from different spatial positions of an inactive sulfide chimney and an active sulfate chimney. For comparison with TOC contents and $\delta^{13} \mathrm{C}_{\mathrm{TOC}}$ values, data of inactive and active chimneys from Manus back-arc basin (Reeves et al., 2014), Loki's Castle of the Arctic Mid-Ocean Ridge (Joao and Menorah) (Jaeschke et al., 2012) and the Southern Mariana Trough (SMT) (Kato et al., 2010) are also plotted together (the vertical lines indicating the ranges of $\delta^{13} \mathrm{C}_{\text {TOC }}$ values and triangles representing the mean values).

surfaces of freshly produced stalks by FeOB species (Chan et al., 2011).

A considerable number of ultrastructures were heavily encrusted with striking surficial morphological architectures such as needle-like architectures (Figures $\mathbf{4 g , h}$ ), thin nanosheets (Figures 5a,c), irregularly tiny grains (Figures 5g,h) and fine burrs (Figures 5j-1). Some thin nanosheets further conglomerated closely and formed flower-like aggregates (Figures 4i-k). EDS analyses showed these surficial architectures were mainly composed of iron (Figures 4n, 5r). These needle-, nanosheet-, bur- and flower-like architectures were ascribed to typical textures of ferrihydrites formed by abiotic chemical $\mathrm{Fe}^{2+}$ oxidization (Zhang et al., 2014). In addition, these modified FeOB-associated ultrastructures also showed a broader diameter range than those from fresh ones, varying from approximately $0.5 \mu \mathrm{m}$ to nearly $5.0 \mu \mathrm{m}$. Formless agglomerates, including globules, flaky aggregates, irregularly shaped blebs and amorphous materials, were common and were primarily attributed to $\mathrm{Fe}$ oxyhydroxides/oxides that were precipitated though the abiotic oxidization of $\mathrm{Fe}^{2+}$.

In addition, differences were observed in terms of microbial architectures among different mineralized tubeworm tubes or even different portions of the same tube. Within the
T-1 tube, yellowish and gray regions showed distinctive ultrastructures (Figures 5a-f). The yellowish portion contained abundant biogenic stalks and filaments with different degrees of mineralization, whereas the gray portion was dominated by many formless aggregates originated from abiotic precipitation, with FeOB-related textures sporadically observed. Moreover, coccoidal forms and their aggregates (Figures 5d,e), primarily composed of sulfur (Figure 5q), were detected only in the gray portion, which indicated the possible occurrence of S-oxidizing microbial groups. Tubular sheaths, whose frequency of occurrence was low in most subsamples of chimney and tubes, were fairly abundant in T3-1 tubes (Figure 5o), whereas heavily mineralized contorted filaments prevailed within the T2-S tube (Figure 5j).

\section{Microbial Community Structures Revealed by 16 S rRNA Gene Pyrosequencing}

A total of 183,410 tags of the bacterial 16S rRNA gene for 17 subsamples were collected from the inactive Milli-Q S10, Milli-Q S10-4, and active young CAP chimneys, and these tags were further clustered into 4,778 OTUs using a 97\% similarity cutoff (Supplementary Table S1). Phylogenetic analysis showed 

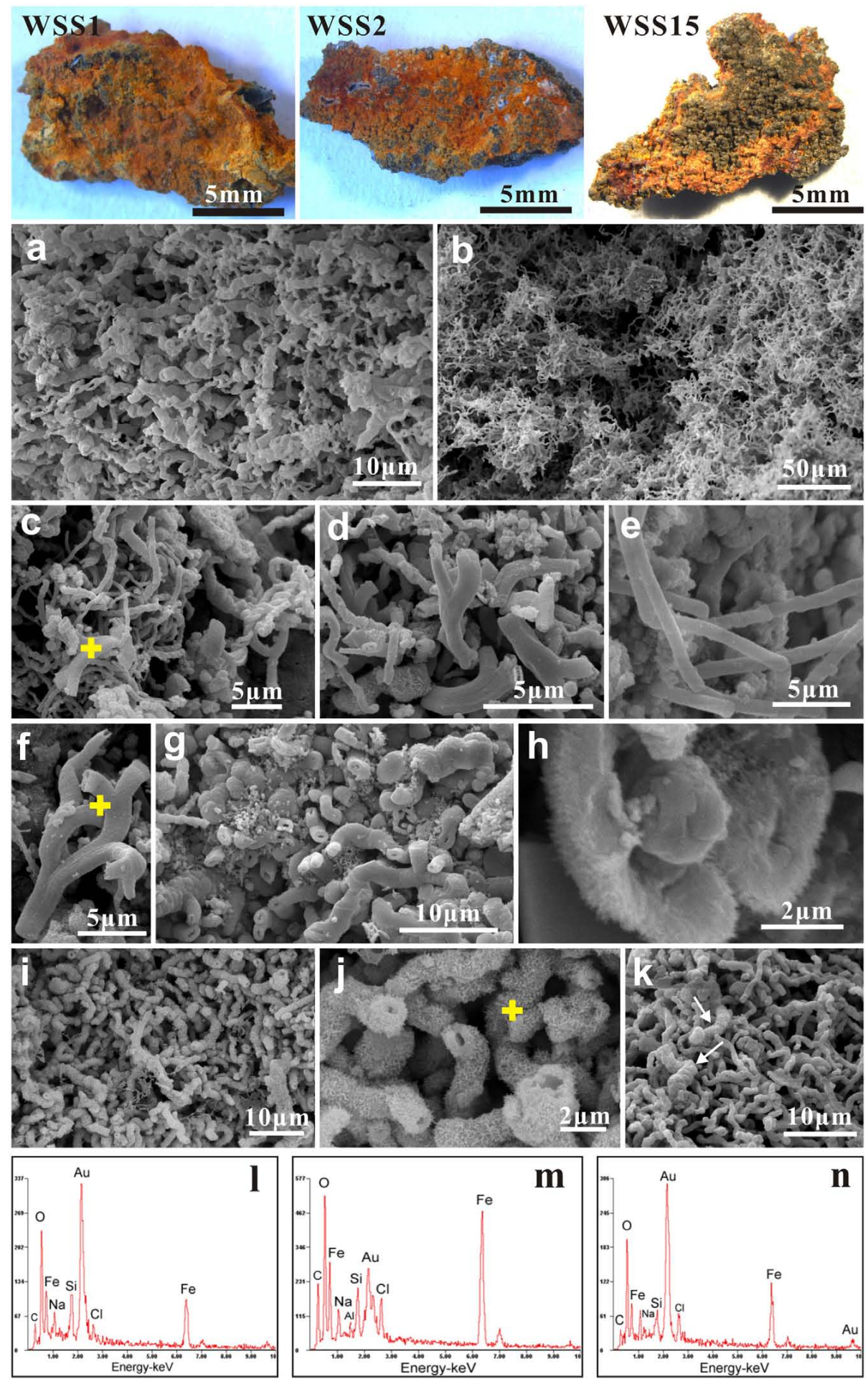

FIGURE 4 | Scanning electron microscopy (SEM) images of weathered inactive sulfide chimney surfaces (WSS1, WSS3, and WSS15). (a,b) Dense aggregates of FeOB-associated ultrastructures such as twisted ribbon-like stalks, branched stalks, straight tubular sheaths and contorted filaments. (c-f) Typical morphologies of Fe-rich ultrastructures induced by known FeOB species. Yellow crosses indicated the positions for EDS analyses. (g) Locally, some branched stalks are heavily encrusted by Fe precipitates. (h) Magnified images of stalk surfaces with tiny needlelike textures. (i,j) Stalks encrusted by bladelike Fe precipitates. Chemical compositions of bladelike textures (yellow cross) was analyzed with EDS. (k) Common occurrence of freshly biogenic stalks and "modified" stalks by abiogenic Fe precipitates. (I, m) EDS spectra of FeOB-associated stalks marked with yellow cross in (c,f), respectively. Iron was the dominant chemical compositions (>50 wt\%), followed by variable amounts of $\mathrm{C}$ and $\mathrm{Si}$. (n) Chemical contents of needle-like and flower-like architectures in (j) which are mainly composed of Fe. 

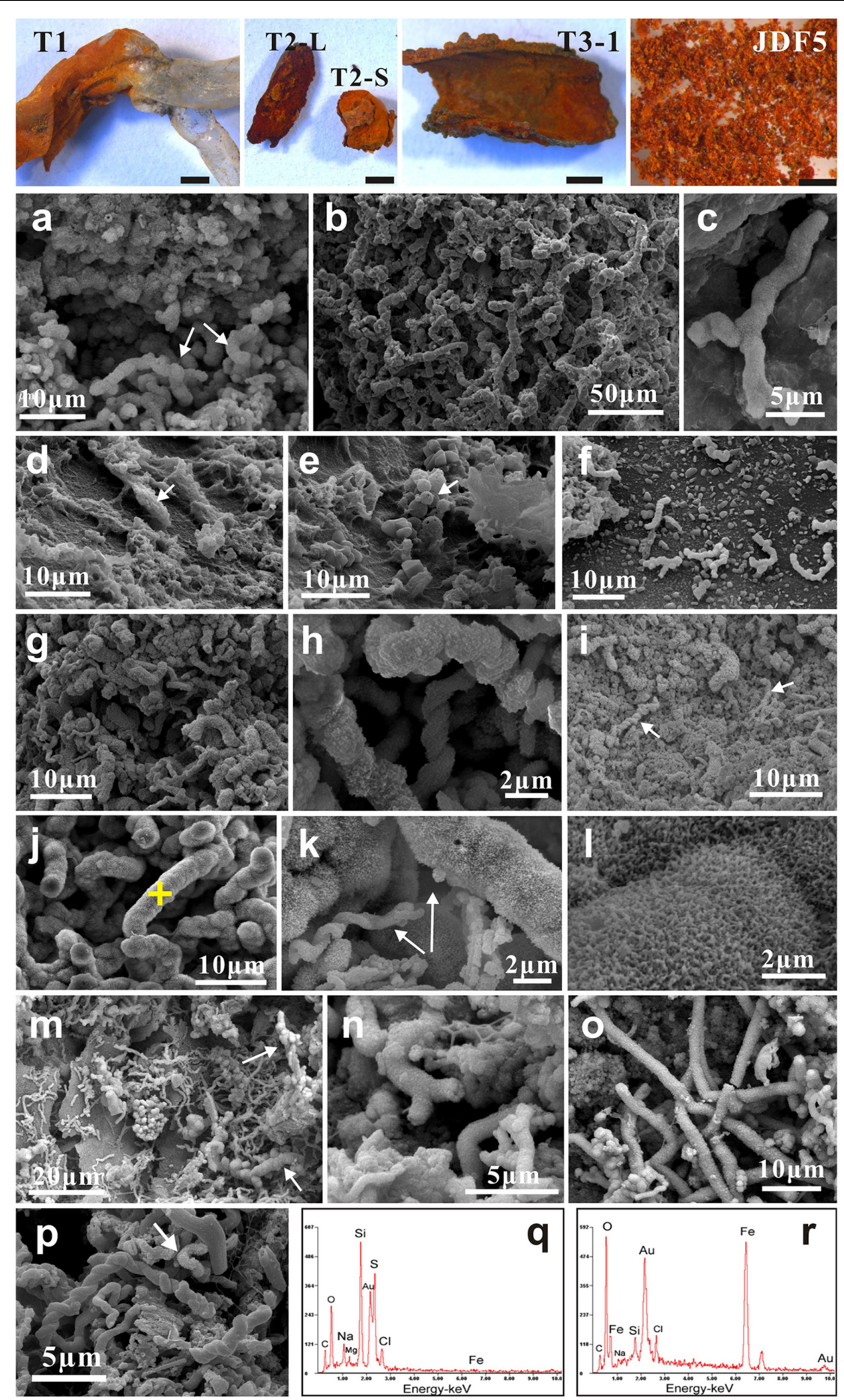

FIGURE 5 | Characteristics of ultrastructures detected from mineralized and fossilized tubes of dead tubeworms, and microbial mats. (a-f) T1 tubeworm. The yellow part contains abundant FeOB-associated stalks and filaments heavily aggregated by tiny Fe-rich flakes (a-c). However, structures produced by FeOB are sporadically scattered in the gray part (d-f). Alternatively, irregularly or spherically S-enriched aggregates (arrows in d,e) are prevailing. (g-l) T2-L and T2-S tubeworms. T2-L's stalks (g-i) are heavily covered by irregularly tiny granules (h) and often buried into amorphous Fe-rich substances (i). T2-S's structures (j-I) are mainly dominated by contorted filaments. Magnified images show that these filaments have acanthaceous surfaces (k,l) and they are remarkably thicker than fresh stalks (arrows). ( $\mathbf{m}-\mathbf{0})$ Typical ultrastructures detected from the fossilized tube wall of T3-1. Abiogenic amorphous Fe-rich precipitations significantly obscure the skeletons of these structures and also thicken them in diameters (m, arrows). (p) Fresh FeOB-associated twisted stalks and structures heavily encrusted by bladelike Fe-rich aggregates (arrow). (q) EDS chemical composition of spherical aggregates in (e), indicating they are enriched in sulfur. (r) EDS spectra of acanthaceous surfaces marked by yellow cross in (j), mainly composed of iron. 


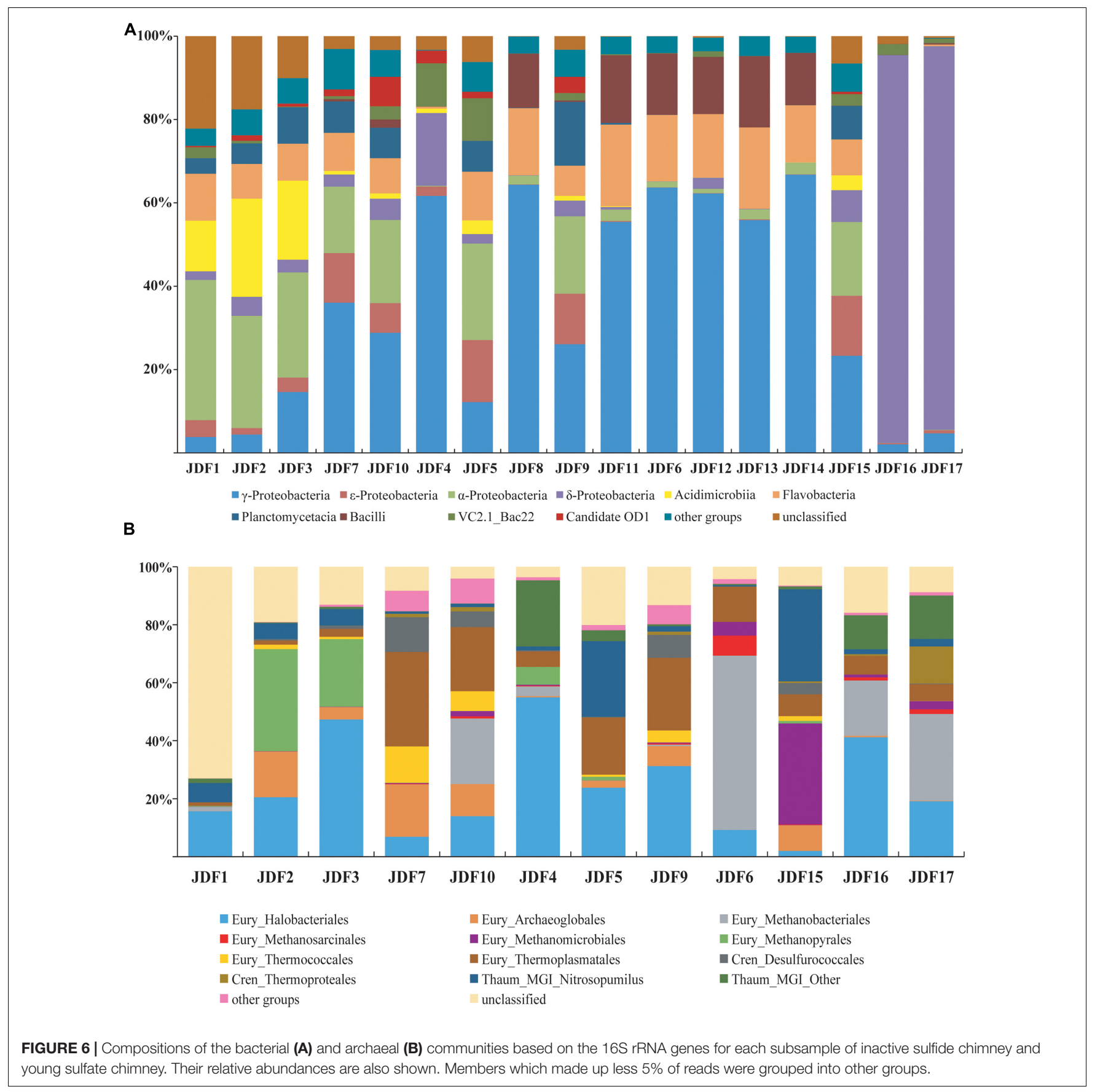

that at the class level, bacterial OTUs were primarily classified into $\alpha-, \gamma-, \varepsilon-$, and $\delta$-Proteobacteria; Bacilli of the phylum Firmicutes; Planctomycetacia of the Planctomycetes; Flavobacteria and uncultured VC2.1_Bac 22 within the Bacteroidetes; and Acidimicrobiia of the phylum Actinobacteria (Figure 6A).

Signatures of $\delta$-Proteobacteria predominantly accounted for more than $90 \%$ of the reads from subsamples JDF16 and JDF17, which had similar community structures; by contrast, within other subsamples, the abundance of $\delta$-Proteobacteria was generally less than 5\% (Figure 6A). Moreover, most signatures detected from JDF16 and JDF17 were exclusively assigned to the order Bdellovibrionales (>90\%) (Supplementary Table S1). Currently, little is known about this lineage (Yilmaz et al., 2016), and it has been suggested that members of this order are primarily found in the epipelagic zone of tropical waters in lower latitudes (DeLong et al., 2006; Pham et al., 2008; Yilmaz et al., 2012). Recently, general molecular surveys of marine bacterial communities have also identified abundant Bdellovibrionalesrelated 16S rRNA gene sequences from deep-sea inactive or low-temperature vents (Sylvan et al., 2012; Meyer et al., 2013). Signatures of $\gamma$-Proteobacteria were among the most common within all samples, and in most cases, they accounted for 
$23 \%$ to nearly $67 \%$ of the bacterial community. The majority of $\gamma$-Proteobacteria further fell into the genera Pseudomonas and Nitrosococcus (Supplementary Table S1). Signatures of $\alpha$ Proteobacteria were also common and relatively abundant. Especially in several outer samples, these components were predominant and accounted for nearly $25-34 \%$ of bacterial compositions (Figure 6A). These members were primarily scattered within the orders Rhizobiales and Rhodobacterales (Supplementary Table S1). Pyrotags affiliating with Bacteroidetes were detected in all inactive sulfide subsamples with relatively uniform and stable abundances ranging between 10 and 21\% of libraries and accounting for less than 3\% of tags within two young sulfate subsamples (Supplementary Table S1). As shown in Figure $\mathbf{6 A}$, most of the Bacteroidetes signatures belonged to the class Flavobacteria. The Firmicutes, whose signatures came from the class Bacilli, were derived from four sulfide samples (JDF6, JDF8, JDF11, and JDF12) and from the young sulfate chimney samples (JDF13 and JDF14) and contributed approximately 13$18 \%$ of bacterial pyrotags within these samples (Supplementary Table S1). Other taxonomic groups, such as, Actinobacteria, $\varepsilon$-Proteobacteria, and Planctomycetes were also common in these subsamples, but their distributions were significantly heterogeneous (Figure 6A). Fe-oxidizing bacterial groups mainly belonged to the genus Mariprofundus of $\zeta$-Proteobacteria and the family Gallionellaceae of $\beta$-Proteobacteria (Supplementary Table S1). Mariprofundus-associated groups were detected in 10 out of the 17 subsamples, and especially in those subsamples from chimney exterior walls and microbial mats (JDF5), their proportions could reach up to $3.5 \%$ (Supplementary Table S1). By contrast, signatures of FeOB members of the Gallionellaceae were detected only from JDF 15 where they represented $\sim 0.3 \%$ of bacterial reads. In addition, a subset of sequence tags belonged to unclassified bacterial clades, suggesting the existence of unknown bacterial populations (Figure 6A).

A total of 73,012 sequence tags of archaeal 16S rRNA genes were obtained for 12 subsamples of the Milli-Q S10 and Milli-Q S10-4 inactive chimneys (Supplementary Table S2). We failed to amplify archaeal sequences from three inactive sulfide subsamples (JDF8, JDF11, and JDF12) of Milli-Q S10 or from two subsamples (JDF13 and JDF14) of the young CAP chimney. Archaea dwelling in inactive chimneys were primarily composed of members of the phyla Euryarchaeota, Thaumarchaeota, and Crenarchaeota (Figure 6B). The Korarchaeota, Nanoarchaeota and Marine Hydrothermal Vent Group-1 (MHVG-1), which is one of the deepest-branching archaeal lineages (Takai and Sako, 1999), were also detected but in low abundance (Supplementary Table S2).

The diversity of the phylum Euryarchaeota was high and contained a series of archaeal groups with different abundances and heterogeneous distributions among subsamples. Signatures of the order Halobacteriales were among the most abundant archaeal populations in these 12 subsamples and in several subsamples their abundance varied from 31 to 55\% (Figure 6B). The majority of these sequences were derived from the Deep-sea Hydrothermal Vent Euryarchaeota Group 6 (DHVEG-6) (Takai and Horikoshi, 1999), which is closely related to the Candidatus "Parvarchaeum" (Baker et al., 2010) (Supplementary Table S2).
Organisms belonging to DHVEG-6 are primarily associated with deep-sea hydrothermal vent systems (Takai and Horikoshi, 1999; Teske and Sørensen, 2008; Li et al., 2014) but have also been found in marine sediment, hypersaline water, fresh water, and anoxic soils (Hugoni et al., 2015). Other minor lineages within the Halobacteriales included the Halobacteriaceae, Deep Sea Euryarchaeotic Group (DSEG), Marine Hydrothermal Vent Group (MHVG), and Miscellaneous Euryarchaeotic Group (MEG) (Supplementary Table S2). The order Thermoplasmatales was also commonly detected in these 12 subsamples but with variable abundances. Within several samples, such as JDF5, JDF7, JDF9 and JDF10, these groups contribute to $20-33 \%$ of reads (Figure 6B). Most of these tags could be further ascribed to the Deep-sea Hydrothermal Vent Euryarchaeotic Group 2 (DHVEG2 ), which is a common and important clade of the microbial community in vent environments (Supplementary Table S2) (Reysenbach et al., 2006). In addition, within the Euryarchaeota, several archaeal lineages were detected that were affiliated with taxa known to be involved in methane cycling including the orders Methanococcales, Methanobacteriales, Methanosarcinales, Methanomicrobiales, and Methanopyrales (Figure 6B), and their relative abundances and distributions were highly variable among different samples. For example, Methanomicrobiales was abundant in only JDF15 where it comprised almost $35 \%$ of reads, whereas signatures of Methanopyrales were abundantly in JDF2 and JDF3, ranging from 23 to $35 \%$ of archaeal reads (Figure 6B). The group for which the highest abundance of signatures was recovered, Methanobacteriales, was detected in JDF6, JDF10, and JDF16-JDF17. In JDF6, $60 \%$ of reads were affiliated to this group (Figure 6). In addition, the remainder of Euryarchaeotic lineages, such as the orders Methanococcales, Methanosarcinales, Archaeoglobales and Thermococcales, appeared to be in low abundance and contributed minimally to overall archaeal profiles in most samples (Supplementary Table S2). The phylum Crenarchaeota was primarily composed of members of Desulfurococcales and Thermoproteales. Although these groups were found in most samples, their abundances were generally not high. As shown in Figure 6B, members of the phylum Thaumarchaeota were also common, and in certain samples, they consisted of $\sim 20$ $33 \%$ of the archaeal communities. Their subclades consisted of the Marine Group I (MGI), Marine Benthic Group A (MBGA), MBG-B, Miscellaneous Crenarchaeotic Group (MCG), Soil Crenarchaeotic Group (SCG), South African Gold Mine Group 1 (SAGMCG-1), Terrestrial Hot Spring Group (THSCG) and pMC2A209 (Supplementary Table S2). Most of the members occurred in the MGI clade (Figure 6 and Supplementary Table S2).

\section{Fe-Oxidizing Bacteria (FeOB)-Associated Bacterial Communities Based on the Construction of 16S rRNA Gene Clone Libraries}

Several sequences closely related to known iron oxidizers were obtained from the 16S rRNA gene clone library (Figure 7). With universal bacterial primers 21F and 1492R (Lane, 1991), 


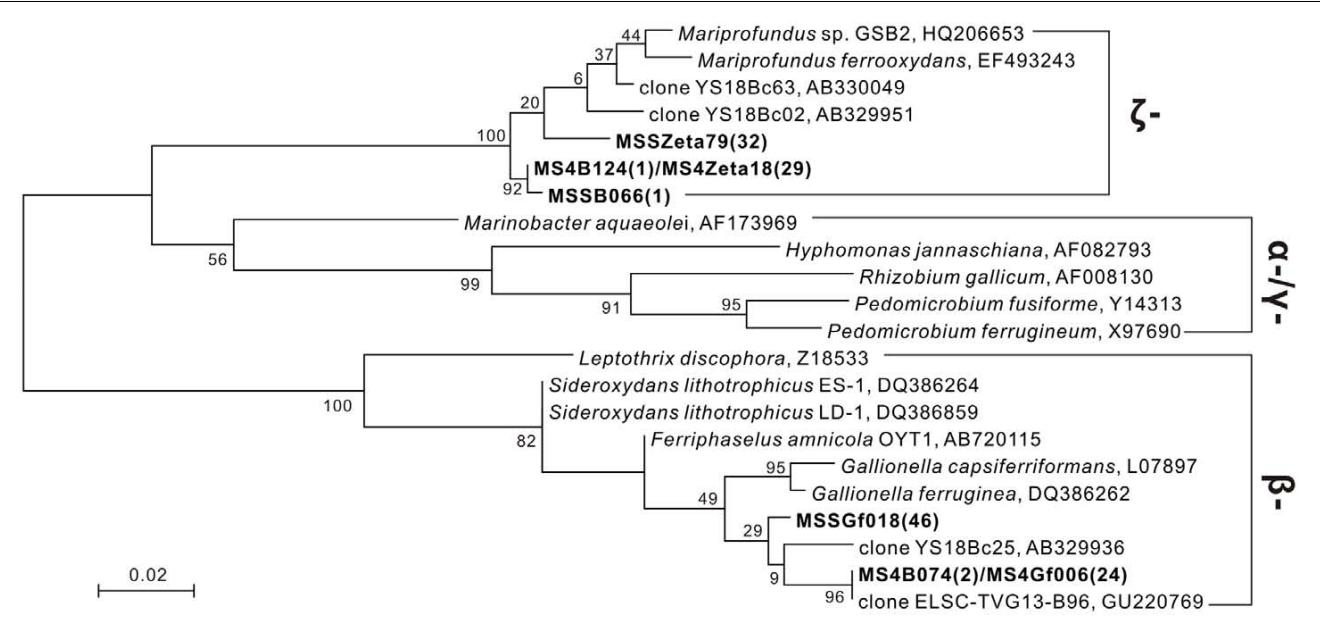

FIGURE 7 | Phylogenetic tree under maximum likelihood criteria of FeOB-associated OTUs (bold) detected from our present study together with other known iron-oxidizing bacterial species and environmental clones (Emerson and Moyer, 2002; Kato et al., 2009, 2014; Li et al., 2012). Sequences of 16S rRNA gene obtained from universal bacterial primers 21F/1492R ( 1.5 kb) and FeOB-specific primers Zeta674F/1492R (800 bp), 122F/998R (900 bp) are combined together to construct the phylogenetic tree. Numbers in brackets indicate the number of clones. Bootstrap support is shown at nodes for 1000 bootstrap replicates under maximum likelihood.

80 and 104 clones were obtained from subsamples JDF1 and JDF5, respectively, and these clones were classified into 48 and 71 OTUs based on $97 \%$ similarity cutoff, respectively. Only two OTUs, MSSB066 and MS4B124 (each representing 1 clone), were detected from JDF1 and JDF5, that showed high similarities to Mariprofundus spp., and were ascribed to the class $\zeta$-Proteobacteria (Figure 7). Another OTU, MS4B074, which represented 2 clones and was closely related to Gallionella spp. affiliated with the class $\beta$-Proteobacteria, was detected from JDF5 (Figure 7).

Specific primers Zeta674F and 1492R were used to target members within the $\zeta$-Proteobacteria (McBeth et al., 2011). 29 and 32 clones were obtained from subsamples JDF1 and JDF5, respectively, and they were clustered into two OTUs, MS4Zeta18 and MSSZeta79. These two OTUs showed close identity (95-96\%) to M. ferrooxydans (Figure 7). MS4Zeta18 was determined to be the same OTU as MS4B124 (above) based on a $97 \%$ similarity cutoff of the $16 \mathrm{~S}$ rRNA gene. Additionally, to capture microbes closely related to Gallionella spp., specific primers $122 \mathrm{~F}$ and 998R were used (Wang J. et al., 2009). 24 and 46 clones were obtained from subsamples JDF1 and JDF5, respectively, and they were clustered into two OTUs, MSSGf006 and MSSGf018. MS4Gf006 was identified as the same OTU as MS4B074 (Figure 7), and they were also nearly identical to two environmental sequences YS18Bc63 and ELSC-TVG13-B96 from the hydrothermal niches of Mariana Trough (Kato et al., 2009) and Lau Basin (Li et al., 2012), respectively, which were classified into the genus Gallionella with $>99 \%$ sequence similarity.

\section{Statistical Results of Principal Coordinates Analysis (PCoA)}

Bacterial and archaeal 16S rRNA gene sequences obtained from pyrosequencing from different chimney parts were subjected to PCoA. As shown in Figure 8, PCoA results for bacterial tag sequences showed that the first two principal components (PC1 and PC2) explained $45.21 \%$ of the total variation and 17 subsamples were roughly grouped into three different clusters. According to the bacterial PCoA plot, subsamples from young active sulfate chimney (JDF13 and 14) clustered together, all exterior subsamples of inactive sulfide chimneys (JDF13, JDF7, JDF10, and JDF15) formed one close group, and three subsamples JDF4, JDF16, and JDF17 did not cluster with the other samples, and formed loosely clustered group. PCoA appearance of these three subsamples is clearly driven by the highest abundance of the $\delta$-Proteobacteria (Figure 6). Subsamples collected from middle layers and inner parts of inactive chimneys were distributed among these three distinct groups (Figure 8). By contrast, archaeal sequences were grouped into four separate clusters by PCoA (Supplementary Figure S4) and did not form obviously distinguishable clusters according to their spatial positions within the inactive chimney.

\section{DISCUSSION}

In this study, numerous Fe-rich ultrastructures with distinctive morphologies and surficial characteristics were commonly observed from outer parts of an inactive sulfide chimney. These structures were attributed to the combined effect of biogenic oxidation of FeOB and abiotic chemical oxidation. Together with mineralogical results, it appears that the inactive sulfide chimney was experiencing oxidative weathering. Microbial community analysis confirmed the occurrence of well-known FeOB groups in subsamples from the inactive sulfide chimney, Mariprofundus spp. within the $\zeta$-Proteobacteria, which are common near low-temperature hydrothermal vents and Gallionella-associated members generally detected from terrestrial fresh water instead of marine niches. Moreover, although hydrothermal venting had 


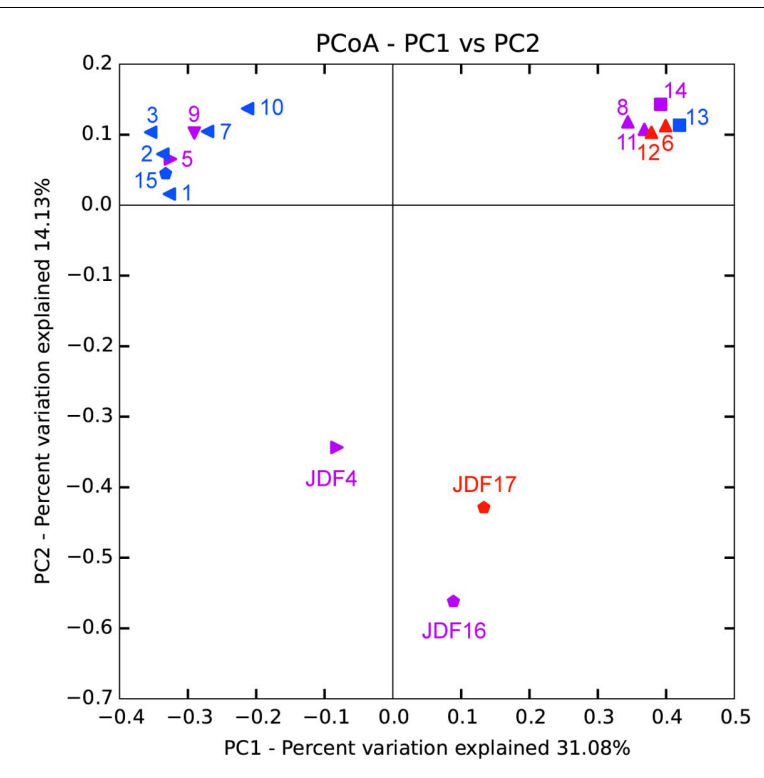

FIGURE 8 | Principal component analysis (PCoA) of bacterial 16S rRNA gene sequences obtained from different spatial positions of inactive sulfide chimneys and active young sulfate chimney. Triangle: subsamples from Milli-Q S10; Pentagen: subsamples from Milli-Q S10-4; Square: subsamples from CAP. Red: subsamples from inner parts; Purple: subsamples from middle layers; Blue: subsamples from exterior walls.

ceased, the inactive sulfide chimney appears to still accommodate diverse microbial populations.

\section{Oxidative Weathering of Inactive Sulfide Chimneys and Involved Fe-Oxidizing Bacterial Groups}

Oxidative weathering of hydrothermal inactive sulfide structures and deposits is prevalent on the modern seafloor. As the result of high-temperature hydrothermal activities, a variety of sulfide minerals are precipitated and further develop into chimney-like structures and massive sulfide deposits that are highly enriched in various reduced forms of metals, including sulfur as well as other elements. Once hydrothermal activities cease, these reduced compounds are exposed to low-temperature, oxygenated seawater, resulting in oxidative weathering reactions (Edwards et al., 2005). The products of seafloor oxidative weathering of sulfide minerals include secondary hydrous alteration minerals, including a variety of Fe oxyhydroxides or oxides together with a few clay minerals, jarosite and atacamite (Pichler et al., 1999; Rogers et al., 2003; Edwards et al., 2004). In some cases, weathered mineral assemblages accumulate extensively on top of massive sulfide deposits as crusts or caps up to several tens of centimeters thick to form gossans (Hannington, 1993; Herzig and Hannington, 1995). In the present study, evidence is seen of oxidative weathering on an inactive sulfide chimney. On the surface, the inactive chimney walls displayed obvious corrosion features and were commonly covered by yellow to reddish-brown alteration products (Figure $\mathbf{1}$ and Supplementary Figure S2). These products also filled the fractures, pits, pores and void spaces in the chimney walls. Analysis of mineral components of these alteration products based on XRD and FT-IR determinations (Figure 2), together with EDS analyses revealed that they are primarily composed of Fe and $\mathrm{O}$ (Figures 4, 5), indicative of Fe oxyhydroxides/oxides.

The prevalence of FeOB-associated ultrastructures suggests that Fe-oxidizing species played an important role in oxidative weathering of inactive hydrothermal chimney. Textural observations of altered chimney surfaces revealed that they consisted of Fe-rich twisted or branched stalks, tubular sheaths and contorted filaments (Figure 4). Based on their distinctive morphologies and compositions, these ultrastructures closely resemble the biogenic Fe oxides of several known FeOB species, including M. ferrooxydans, G. ferruginea, and L. ochracea (Emerson et al., 2010; McAllister et al., 2011). It has been shown that $\mathrm{Fe}$ oxidizers can directly use different sulfide mineral substrates and actively facilitate the weathering processes (McCollom, 2000; Edwards et al., 2003a,b). Generally, these Fe-oxidizing species are strictly microaerophilic, and hence, it appears that the well-oxygenated seawater that surrounds inactive chimneys does not support their growth. In fact, $\mathrm{O}_{2}$ utilizing populations initially colonize the surfaces of inactive chimneys (Edwards et al., 2003a; Rogers et al., 2003) and reduce surface oxygen to levels that FeOB species favor such that they can effectively compete with rapid abiotic $\mathrm{Fe}^{2+}$ oxidation. Once Fe oxidizers inhabit the surface and their Fe-oxide crusts are produced, they are partially protected from the oxidative exchanges with seawater (Edwards et al., 2005). In addition, the oxidation of $\mathrm{Fe}$ and $\mathrm{S}$ is estimated to supply the most abundant energy sources for chemolithoautotrophs in seafloor environments because of their high abundances in basalt and metal sulfides (Bach and Edwards, 2003; Edwards et al., 2005), which, to a large extent, explains the wide distribution of $\mathrm{FeOB}$ species within the alteration products of seafloor rocks and sulfide deposits in the ocean crust (Perfit et al., 2003; Rogers et al., 2003; Orcutt et al., 2011).

Fe-oxidizing bacteria-involved biomineralization also commonly occurs within the tubes of dead tubeworms. It has been demonstrated that near hydrothermal vents, tubeworms can remarkably influence metal distribution, and that sulfide minerals (especially iron sulfides) accumulate on surfaces or are entombed within the tube interlayers during tube-building episodes (Maginn et al., 2002; Peng et al., 2009). With the process of mineralization, certain tubes are gradually replaced by pyrite and marcasite and become completely fossilized (e.g., tube T3-1, Figure 5). When these tube structures are exposed to seawater, oxidative alterations of various Fe-rich sulfide minerals prevail. Abundant FeOB-associated ultrastructures were also commonly detected on these tubeworm tubes (Figure 5).

However, as noted in Figure 5, a series of delicate $\mathrm{Fe}$ rich surface textures such as tiny grains, fine burrs and thin nanosheets on the exteriors of FeOB-related ultrastructures of mineralized tubeworm tubes (Figures $\mathbf{5 c}, \mathbf{h}, \mathbf{l}, \mathbf{n}$ ), which are ascribed to the rapid abiotic oxidation of $\mathrm{Fe}^{2+}$ instead of microbial activity, indicates that an environmental shift occurred within the tubes from the FeOB-favorable microoxic condition to fully oxygenated niches. Generally, within chimney walls, tube 
structures of tubeworms create ample fluid conduits through which inward penetration of seawater and outward percolation of dissolved substances within the chimney (hydrothermal fluids are also included) cause intensive and dynamic mixing and further influence the thermal and chemical gradients within the chimney walls (Koski et al., 1984; Cook and Stakes, 1995). Tube T1, which was divided into yellow and gray portions (Figure 5), provides an example of the outward transportation of dissolved substances of the chimney. In the yellow portion, Fe oxyhydroxides consisting of FeOB-associated ultrastructures are abundant, whereas they are seldom found in the gray portion. The boundary between yellow and gray roughly indicates the positions at which $\mathrm{Fe}^{2+}$ was dissolved and extracted from sulfide minerals by iron oxidizers colonizing the tube surface. A similar situation occurs on the exterior surfaces of chimney walls, where needle-like and flower-like architectures enwrap the FeOB-associated structures (Figures $4 \mathbf{h}, \mathbf{j}$ ) and are also attributed to abiotic $\mathrm{Fe}^{2+}$ oxidation. The precipitation and accumulation of Fe-rich substances caused by this type of abiotic $\mathrm{Fe}^{2+}$ oxidation may cause these FeOBassociated structures to expand outward (Figures $4 \mathbf{h}, \mathbf{j}, \mathbf{5 k}, \mathbf{n}, \mathbf{o}$ ). In certain cases, intensive abiotic Fe precipitation can obscure and modify the original shapes and morphologies of biotic structures, or even submerge them to an extent (Figure 5i). The coexistence of fresh $\mathrm{FeOB}$-associated ultrastructures and those modified by $\mathrm{Fe}^{2+}$ oxidation (Figures $\mathbf{4 k}, \mathbf{5} \mathbf{k}$ ) indicates that the interfaces at which sulfide mineral assemblages of the inactive chimney actively react with seawater are highly dynamic and alterative. Depending on the dissolved $\mathrm{O}_{2}$ concentrations, $\mathrm{FeOB}$ species and abiotic oxidization alternatively dominate the formation of $\mathrm{Fe}$ oxyhydroxides. Recently, a study based on the Fe mineralogy and isotope data also reveal similar dynamic microenvironments in seafloor sulfide-mineral deposits with variable redox conditions causing a dynamic range of Fe transformation pathways (Toner et al., 2016). In addition, nanostructures of Fe oxyhydroxides and oxides are sensitive to changes in environmental conditions (Guo and Barnard, 2013; Zhang et al., 2014). Therefore, distinct characteristic morphologies on the surfaces of FeOBassociated ultrastructures infer considerably heterogeneous microenvironments with different physicochemical natures on the inactive sulfide chimney walls.

Phylogenetic analyses suggest that iron oxidizers dwelling within inactive chimneys consist of members of the genus Gallionella and the class $\zeta$-Proteobacteria. Tags affiliated with the family Gallionellaceae account for approximately $0.3 \%$ of the total tags on JDF15 (Supplementary Table S1), and clone libraries of JDF5 contain at least three OTUs that are closely associated with G. ferruginea (Figure 7). In previous studies, members of the genus Gallionella were seldom detected with microbiological evidence from the seafloor environments (Edwards et al., 2003a; McAllister et al., 2011). Although twisted ribbon-like stalks are commonly assigned as the biosignature of the Gallionella spp. in biogenic iron oxyhydroxides from hydrothermal fields (Fortin et al., 1998; Kennedy et al., 2003; Edwards et al., 2004), a low occurrence of Gallionella-like microbes and the new finding that $M$. ferrooxydans can produce almost identical structures (Emerson and Moyer, 2002) have led researchers to argue that twisted ribbon-like stalks on the seafloor should be attributed to members of $\zeta$-Proteobacteria (primarily consisting of M. ferrooxydans and its relatives) instead of Gallionella spp., which are widely distributed in terrestrial freshwater niches rather than marine environments. Our results, together with several phylotypes closely related to Gallionella spp. recently obtained from the low-temperature Fe-rich precipitates (Kato et al., 2009; Li et al., 2012), suggest that Gallionella spp. indeed exist in deep-sea hydrothermal vents. More recently, Sylvan et al. (2012) revealed that up to $1 \%$ of tag sequences were closely related to Gallionella spp. and were one of the most common tags detected from an inactive hydrothermal sulfide chimney. A roughly similar situation also occurs regarding the tubular sheaths that are commonly ascribed to L. ochracea. No sequences related to this taxon have yet been recovered from hydrothermal chimneys (Emerson and Ghiorse, 1992; McAllister et al., 2011). In a recent study, it was observed that the tubular sheaths were most likely produced by the members of $\zeta$-Proteobacteria instead of $L$. ochracea or other iron-oxidizing $\beta$-Proteobacteria in the veillike surface layers of the mats at Loihi Seamount (Fleming et al., 2013). More recently, a series of cultivation showed that this kind of tubular sheaths is indeed produced by $\zeta$-Proteobacteria (Barco et al., 2017). Combined with the fact that no Leptothrix-related species were detected, and members within $\zeta$-Proteobacteria were common (Supplementary Table S1), tubular sheaths within our inactive chimneys (Figure 4) are attributed to the products of $\zeta$-Proteobacteria. Tags closely related to $M$. ferrooxydans within $\zeta$-Proteobacteria were commonly distributed among most of the subsamples. Since its initial discovery (Emerson and Moyer, 2002), M. ferrooxydans has primarily been found from various iron oxyhydroxide deposits near the hydrothermal vent, basalt and oceanic crust (Emerson et al., 2010). Several recent studies revealed that $M$. ferrooxydans could also be distributed in near-shore and estuarine environments (McBeth et al., 2011; Dang et al., 2014). Taken together, the findings suggest that although morphologic evidence is frequently used to indicate the activity of $\mathrm{Fe}$ oxidizers, and although ultrastructures with different morphologies have been linked phylogenetically to specific FeOB species (Kennedy et al., 2003; Emerson et al., 2010), morphological signatures are at times not reliable for distinguishing certain specific iron-oxidizing species, and true microbiological evidence is still required.

\section{Microbial Communities Dwelling within Inactive Sulfide Chimneys}

Total organic carbon contents of our inactive chimney (0.04$1.91 \%)$ are comparable to or even higher than those of active chimneys (Figure 3), implying high microbial biomass and active microbial activity within the chimney samples investigated here. It has been suggested that, in general, active hydrothermal structures contain TOC concentrations ranging from 0.02 to 1.0 wt\% (Kato et al., 2010; Jaeschke et al., 2012, 2014; Reeves et al., 2014) and occasionally, local patchy areas have high TOC content of nearly $3.0 \mathrm{wt} \%$ (Jaeschke et al., 2012). To a certain degree, values of $\delta^{13} \mathrm{C}_{\mathrm{TOC}}$ can roughly reflect the chemolithoautotrophic activities in such habitats (Kato et al., 2010; Jaeschke et al., 2014). Several exterior subsamples of the inactive chimney Milli-Q S10 
show the lowest $\delta^{13} \mathrm{C}_{\text {TOC }}$ values $(-31.39$ to $-29.48 \%$ ) with TOC concentrations that are also high (0.13-0.31 wt\%) (Figure 3), suggesting that in these exterior portions, chemolithoautotrophic activities (for example, FeOB-associated oxidation of chimney minerals) might be higher than those in the middle and interior portions. In this work, we do not exclude the influence of organic remains originating from microbial inhabitants and symbiotic autotrophic lineages of invertebrates within the chimney before the hydrothermal supply ceased. In addition, the $\delta^{13} \mathrm{C}_{\mathrm{TOC}}$ values of the inactive chimney are usually low $(-31.4$ to $-21.2 \%$ ) compared with those of active chimneys previously reported $(-21.4$ to $-15.5 \%$ ) , possibly attributed to heterotrophic carbon consumption by heterotrophs (Kato et al., 2010; Reeves et al., 2014). In addition, these strong variations in TOC contents and $\delta^{13} \mathrm{C}_{\mathrm{TOC}}$ values within different spatial positions indicate that inactive chimney actually hosts quite heterogeneous habitats for microbes.

Inactive sulfide chimney still accommodates flourishing and diverse microbiomes. When the supply of hydrothermal fluid ceases, environmental conditions across chimneys change, resulting in a corresponding shift in the microbiome. Bacterial populations within the inactive chimney investigated here primarily consist of members of $\delta$ - and $\gamma$-Proteobacteria, together with relatively abundant and varying proportions of members within $\alpha$-Proteobacteria, Bacteroidetes, Actinobacteria, Firmicutes, and Planctomycetes (Figure 6A). These bacterial components are either seldom detected from active hydrothermal vents or occur but with quite low abundances. For example, most of the tags of $\delta$-Proteobacteria were classified into the order Bdellovibrionales (Supplementary Table S1), whose members prey exclusively on other bacteria (Schoeffield and Williams, 1990) and are ubiquitously found in various marine environments such as seawater and sediments (Welsh et al., 2015; Yilmaz et al., 2016). Recently, although members of Bdellovibrionales were detected from seafloor vents, they occurred only in inactive sulfide chimneys similar to ours (Sylvan et al., 2012) and rather low-temperature $\left(<15^{\circ} \mathrm{C}\right)$ "snowblower" hydrothermal vents (Meyer et al., 2013). Within $\gamma$-Proteobacteria, tags affiliated with the genus Nitrosococcus which is known as typical ammonia-oxidizing bacteria (AOB), commonly occur in the inactive chimney with less than $5 \%$ proportions, but they are the most abundant bacterial populations in JDF4, in which they were detected in nearly $54 \%$ of tags recovered (Supplementary Table S1). Within the subsample JDF4, tags affiliated to the genus Desulfobulbus of $\delta$-Proteobacteria are also abundant with more than $15 \%$ proportions. Members of the Desulfobulbus comprise strictly anaerobic, sulfate reducers utilizing sulfate (sulfite or thiosulfate) as the terminal electron acceptor with the oxidation of organic compounds (chemoorganotroph) (Kuever et al., 2015). There is a large number of tags within the genus Pseudomonas together with minor members of the genera Acinetobacter and Flavobacterium. All these groups are putative denitrifiers. Interestingly, these three taxa are abundantly distributed within the same spatial areas within the active chimneys and are the dominant bacterial populations ( $\sim 60 \%$ of reads) within the relatively inner regions such as JDF11, JDF8, JDF6 and JDF12, and the actively young CAP sulfate chimney. Nitrite oxidizers within the inactive chimneys are mainly represented by two bacterial genera, the genus Nitrospira of the phylum Nitrospira and the genus Nitrospina of $\delta$-Proteobacteria. Compared with other participants of $\mathrm{N}$-cycling noted above, their distribution is limited among the chimneys; moreover, their abundance is generally less than $0.5 \%$ of total tags, and within the outmost surfaces, their proportion might be near only $1 \%$ (Supplementary Table S1). Based on phylogenetic analyses of bacterial communities, it is inferred that they are potentially involved in a diverse set of geochemical processes including iron oxidation (Gallionella spp. and Mariprofundus spp.), methane oxidation (Methylococcales of $\gamma$-Proteobacteria), nitrogen fixation (e.g., Rhizobiales of $\alpha$-Proteobacteria), ammonia oxidation (e.g., Nitrosococcus of $\gamma$-Proteobacteria) and denitrification (Pseudomonas of $\gamma$-Proteobacteria), which indicates that diverse nutrient supplies are available compared with active sulfide chimneys that to a great extent depend on sulfur oxidization (Campbell et al., 2006; Kormas et al., 2006; Li et al., 2014). A similar situation occurs with archaeal community structures. In three subsamples of inactive chimney material no archaeal tags were detected successfully, suggesting the low biomass and restricted distribution of archaea within inactive chimney. By contrast, in active hydrothermal chimneys, archaea are generally abundant (Schrenk et al., 2003; Kormas et al., 2006; Li et al., 2014). Mesophilic archaea, for example, members of the Thaumarchaeota, are abundant within the inactive chimney, even in their middle and inner parts (Figure 6B), which suggests decreasing temperatures within inactive chimneys as high-temperature fluid supply stops. Inhabitants of inactive chimney, especially bacterial and thaumarchaeotal taxa, may start to largely reflect normal marine seawater and sediment communities as venting ceases. In the process of colonization from surrounding seawater and sediments, the mineralogy and degree of exposure to seawater likely selects for specific bacterial communities (Edwards et al., 2003a; Toner et al., 2013). This notion is supported by the observation that taxonomic signatures of bacteria within most samples from the outer surface of the inactive chimney cluster together (Figure 8).

The detection of diverse archaeal communities within the inactive chimney, especially the prevalence of thermophilic and hyperthermophilic taxa (Figure 6B), was unexpected. Previously, archaeal populations were generally absent from inactive chimneys, indicating archaea might not be important in the weathering of minerals and rocks on the seafloor relative to bacteria (Edwards et al., 2003a; Rogers et al., 2003; Kato et al., 2010; Sylvan et al., 2012; Reeves et al., 2014). Recently archaeal taxa were shown to represent only a small proportion of the microbiome in inactive chimneys (below detection or $<0.2 \%$ ) (Sylvan et al., 2013). Although archaeal populations appeared within our inactive chimney subsamples, there were a couple of inactive chimney subsamples from which no archaeal tags were obtained, indicating archaeal signatures were likely in low abundance. When hydrothermal activities cease, inactive chimney walls are surrounded by low-temperature seawater, conditions not favorable for thermophiles. Two possibilities may explain the detection of signatures of thermophiles. One is that the supply of high-temperature fluids ceased only recently, and 


$$
\text { A Early stage: young sulfate chimney }
$$

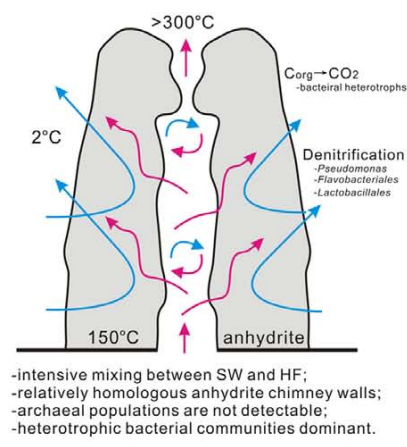

B Mature stage: active sulfide chimney

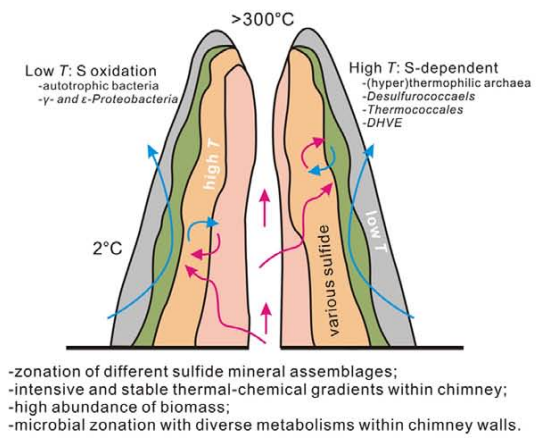

C Inactive stage: weathering sulfide chimney

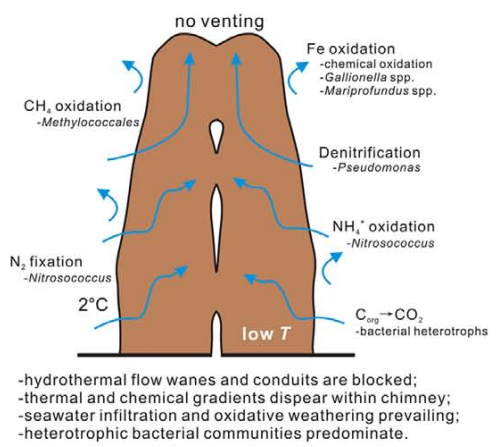

FIGURE 9 | Conceptual model of microbial succession at different stages of hydrothermal chimney evolution. The characteristics of physical-chemical conditions, microbial population, and involved geochemical processes are included. The data of early stage (A) and inactive stage (C) come from our present study and mature stage (B) depends mainly on previous work (Li et al., 2014).

these thermophilic DNA signatures are the remains of previous archaeal colonizers that inhabited the hot active chimney. Another possibility is that these thermophiles are sourced from sub-seafloor hydrothermal habitats and are subsequently transported into inactive chimneys within periodic pulses of low-temperature fluid from below the ridge flank. Recently, new findings suggest that ecologically unique high-temperature archaeal reservoirs exist beneath ridge flanks (Kormas et al., 2003; Ehrhardt et al., 2007; Edwards et al., 2011) in which crustal fluids support these active indigenous communities (Cowen et al., 2003; Huber et al., 2006; Engelen et al., 2008). PCoA analysis of archaea shows that subsamples were not separated by their spatial zonation (Supplementary Figure S4), especially exterior samples. This supports to some degree the possibility that they come from deep beneath the seafloor and are randomly distributed within the inactive chimney.

\section{Microbial Colonization within the Young Sulfate Hydrothermal Chimney and Microbial Succession during Chimney Evolution}

Microbial communities within the CAP sulfate chimney reflect early colonizers during the formation of a hydrothermal chimney. As noted above, the CAP chimney walls are porous and primarily composed of anhydrite (Table 1). The mineralogical compositions, i.e., the absolute dominances of sulfate minerals, indicate that the CAP chimney is still in the young first formation stage (Tivey, 1995), although its exact age was not determined in the present study. In situ growth experiments that simulate chimney formation showed that young hydrothermal chimneys with sulfate mineral assemblages that are roughly similar to the current CAP chimney could be quickly deposited and welldeveloped within several days to months (Page et al., 2008; Wang F. et al., 2009). Our microbial analyses revealed that microbial signatures associated with this chimney were dominated by members of $\gamma$-Proteobacteria, followed by Bacteroidetes and the Firmicutes, and no archaeal components were detected
(Figure 6A and Supplementary Table S1). Heterotrophic bacterial populations, including members of the orders Pseudomonadales, Flavobacteriales, and Lactobacillales represent more than 85\% of sequenced tags (Supplementary Table S1). This contrasts with previous observations showing the general prevalence of autotrophic $\varepsilon$-Proteobacteria (Reysenbach et al., 2000; LópezGarcía et al., 2003; Alain et al., 2004). The most likely explanation for the dominance of heterotrophs is that a rapid shift has occurred from autotrophs to heterotrophs within this young sulfate chimney. As primary producers, chemolithoautotrophs are likely the first colonizers to occupy exposed surfaces within sulfate chimneys. Once sufficient organic carbon accumulates, heterotrophic bacterial lineages may emerge and replace the autotrophs as the dominant taxa (Reysenbach et al., 2000). Variation in microbial succession can occur within hours, days, or months (Reysenbach et al., 2000; Nercessian et al., 2003; Page et al., 2008). In addition, the absence of archaeal clades from this nascent chimney is consistent with previous in situ colonization observations (López-García et al., 2003). In situ temperature is expected to be one of the crucial constraints on microbial colonization (Alain et al., 2004). Most archaeal lineages near hydrothermal vents generally consist of thermophiles or hyperthermophiles that inhabit the hottest areas of the chimney. Although the CAP chimney is active, the temperature within most positions of the sulfate chimney walls [especially in the middle and outer regions where we sampled (Figure 1c)] is inferred to be low, which is supported by the lack of hightemperature sulfide mineral assemblages (Table 1). Bacterial signatures from the middle (JDF14) and outer portions (JDF13) are not obviously distinct, indicating their possibly homologous environmental parameters.

Combining microbial communities that inhabit the young CAP sulfate chimney and the inactive sulfide chimney in the current study with those in maturely active sulfide structures collected from the same MEF hydrothermal field in previous investigations (Zhou et al., 2009; Li et al., 2014) provides a rough depiction of the microbial community succession at different stages of hydrothermal chimney aging (Figure 9). 
At the early nascent stage, the chimney is precipitated initially and characterized by the dominant anhydrites. Microbial communities appear to be mainly dominated by heterotrophic bacterial populations, including members of $\gamma$-Proteobacteria together with relatively abundant members of Bacteroidetes and Firmicutes. The abundance of archaeal communities is not high. Moreover, archaeal populations are generally absent from the chimney at this stage because of unfavorable environmental conditions, including low temperatures and high concentrations of oxygen. With the gradual precipitation of diverse sulfide minerals, the mature chimney is solidified and dominated by high-temperature mineral assemblages. Correspondingly, the microbial community structure changes dramatically. Bacterial compositions primarily consist of autotrophic members of $\varepsilon$-Proteobacteria, whereas archaeal members are dominated by thermophiles and hyperthermophiles generally involved in sulfur cycling (Zhou et al., 2009; Li et al., 2014). Microbial abundance and taxonomic composition varies significantly along the profile of an active chimney from the outer surfaces to the inner regions close to the central hydrothermal conduits ( $\mathrm{Li}$ et al., 2014). Finally, with waning and cessation of hydrothermal activity, energy supporting the microbial populations changes from the extensive chemical disequilibrium between seawater and hydrothermal fluid to sulfide weathering and decomposition of organic remains. At this stage, bacterial communities appear dominated by members of $\gamma$-Proteobacteria, followed by Bacteroidetes and Firmicutes. These bacterial clades primarily consume pre-formed organic materials. Where $\mathrm{Fe}$ rich sulfide minerals interact with seawater, autotrophic FeOB appear to flourish. At the same time, archaeal members gradually disappear with the waning of hydrothermal supplies, and certain mesophilic archaeal components such as Thaumarchaeota remain. However, in selected situations, pulses of low-temperature fluids may carry thermophilic and hyperthermophilic species derived from deep niches into inactive chimneys.

\section{CONCLUSION}

In this study, the oxidative weathering and microbial diversity of an inactive hydrothermal sulfide chimney and a young, active chimney were analyzed. Oxidative weathering commonly occurred on the inactive sulfide chimney. Fe oxidizers closely related to Gallionella spp. and Mariprofundus spp. appear to promote this process based on abundant remains

\section{REFERENCES}

Alain, K., Zbinden, M., Le Bris, N., Lesongeur, F., Querellou, J., Gaill, F., et al. (2004). Early steps in microbial colonization processes at deep-sea hydrothermal vents. Environ. Microbiol. 6, 227-241. doi: 10.1111/j.1462-2920. 2003.00557.x

Anderson, R. E., Sogin, M. L., and Baross, J. A. (2015). Biogeography and ecology of the rare and abundant microbial lineages in deep-sea hydrothermal vents. FEMS Microbiol. Ecol. 91, 1-11. doi: 10.1093/femsec/ fiu016 of distinctive Fe-rich ultrastructures. At the same time, a series of characteristic tissues encrusted on the surface of FeOB-associated ultrastructures and ascribed to abiotic $\mathrm{Fe}^{2+}$ oxidization are distinguished, and their coexistence indicates that oxidative weathering is a dynamic process with environmental parameters that are continuously varying. Phylogenetic analysis of pyrotag sequences suggests that inactive sulfide chimneys can still accommodate abundant and diverse microbial populations even though the hydrothermal supply has ceased, but composition and inferred metabolic potential significantly differ from those of an active high-temperature sulfide chimney.

\section{AUTHOR CONTRIBUTIONS}

JL and HZ designed the research. JL and QY subsampled the chimneys. JC, BW, and ZW conducted electron microscopic analyses, mineralogical contents and TOC determinations. JL, GC, and YW performed molecular diversity analyses. JL and HZ wrote the manuscript. All authors contributed to interpretation of data.

\section{FUNDING}

This work was financially supported by the National Natural Science Foundation of China (NSFC, No. 41472307), the National Basic Research Program of China (973 Program, No. 2012CB417300), the Strategic Priority Research Program of Chinese Academy of Sciences (No. XDB06010201), and the Hainan International Collaborative Grant (KJHZ2015-22).

\section{ACKNOWLEDGMENTS}

We greatly appreciate the efforts and assistance of Dr. Virginia Edgcomb (Woods Hole Oceanographic Institution) in revising our manuscript and thank Dr. Hu Wang and Dr. Fuwu Ji (Tongji University) in collecting chimney samples.

\section{SUPPLEMENTARY MATERIAL}

The Supplementary Material for this article can be found online at: http://journal.frontiersin.org/article/10.3389/fmicb. 2017.01378/full\#supplementary-material

Bach, W., and Edwards, K. J. (2003). Iron and sulfide oxidation within the basaltic ocean crust: implication for chemolithoautotrophic microbial biomass production. Geochim. Cosmochim. Acta 67, 3871-3887. doi: 10.1016/S00167037(03)00304-1

Baker, B. J., Comolli, L. R., Dick, G. J., Hauser, L. J., Hyatt, D., Dill, B. D., et al. (2010). Enigmatic, ultrasmall, uncultivated Archaea. Proc. Natl. Acad. Sci. U.S.A. 107, 8806-8811. doi: 10.1073/pnas.0914470107

Barco, R. A., Hoffman, C. L., Ramírez, G. A., Toner, B. M., Edwards, K. J., and Sylvan, J. B. (2017). In situ incubation of iron sulfur mineral reveals a diverse chemolithoautotrophic community and a new biogeochemical role for 
Thiomicrospira. Environ. Microbiol. 19, 1322-1337. doi: 10.1111/1462-2920. 13666

Boyd, T., and Scott, S. D. (1999). Two-XRD-line ferrihydrite and Fe-Si-Mn oxyhydroxide mineralization from Franklin Seamount, western Woodlark Basin, Papua New Guinea. Can. Mineral. 37, 973-990.

Brazelton, W., Schrenk, M., Kelley, D., and Baross, J. A. (2006). Methaneand sulfur-metabolizing microbial communities dominate the Lost City hydrothermal field ecosystem. Appl. Environ. Microbiol. 72, 6257-6270. doi: 10.1128/AEM.00574-06

Campbell, B. J., Summers Engel, A., Porter, M. L., and Takai, K. (2006). The versatile $\varepsilon$-proteobacteria: key players in sulphidic habitats. Nat. Rev. Microbiol. 4, 458-468. doi: 10.1038/nrmicro1414

Chan, C. S., Fakra, S. C., Emerson, D., Fleming, E. J., and Edwards, K. J. (2011). Lithotrophic iron-oxidizing bacteria produce organic stalks to control mineral growth: implications for biosignature formation. ISME J. 5, 717-727. doi: 10. 1038/ismej.2010.173

Cook, T. L., and Stakes, D. S. (1995). Biological mineralization in deep-sea hydrothermal deposits. Science 267, 1975-1979. doi: 10.1126/science.267.5206. 1975

Corliss, J. B., Dymond, J., Gordon, L. I., Edmond, J. M., von Herzen, R. P., Ballard, R. D., et al. (1979). Submarine thermal springs on the Galapagos Rift. Science 203, 1073-1083. doi: 10.1126/science.203.4385.1073

Cowen, J. P., Giovannoni, S. J., Kenig, F., Johnson, H. P., Butterfield, D., Rappe, M. S., et al. (2003). Fluids from aging ocean crust that support microbial life. Science 299, 120-123. doi: 10.1126/science. 1075653

Dang, H., Chen, R., Wang, L., Shao, S., Dai, L., Ye, Y., et al. (2014). Molecular characterization of putative biocorroding microbiota with a novel niche detection of Epsilon- and Zetaproteobacteria in Pacific Ocean coastal seawaters. Environ. Microbiol. 13, 3059-3074. doi: 10.1111/j.1462-2920.2011.02583.x

DeLong, E. F., Preston, C. M., Mincer, T., Rich, V., Hallam, S. J., Frigaard, N.-U., et al. (2006). Community genomics among stratified microbial assemblages in the ocean's interior. Science 311, 496-503. doi: 10.1126/science.1120250

Eberhard, C., Wirsen, C. O., and Jannasch, H. W. (1995). Oxidation of polymetal sulfides by chemolithoautotrophic bacteria from deep-sea hydrothermal vents. Geomicrobiol. J. 13, 145-164. doi: 10.1080/01490459509378014

Edwards, K. J., Amend, J. P., and Lyons, T. W. (2004). Sulfur biogeochemistry-past and present. Geol. Soc. Am. Spec. Pap. 379, 1-16.

Edwards, K. J., Bach, W., and McCollom, T. M. (2005). Geomicrobiology in oceanography: microbe-mineral interactions at and below the seafloor. Trends Microbiol. 13, 449-456. doi: 10.1016/j.tim.2005.07.005

Edwards, K. J., McCollom, T. M., Konishi, H., and Buseck, P. R. (2003a). Seafloor bioalteration of sulfide minerals: results from in situ incubation studies. Geochim. Cosmochim. Acta 67, 2843-2856. doi: 10.1016/S0016-7037(03)0 $0089-9$

Edwards, K. J., Rogers, D. R., Wirsen, C. O., and McCollom, T. M. (2003b). Isolation and characterization of novel psychrophilic, neutrophilic, $\mathrm{Fe}$ oxidizing, chemolithoautotrophic $\alpha$ - and $\gamma$-Proteobacteria from the deep sea. Appl. Environ. Microbiol. 69, 2906-2913.

Edwards, K. J., Wheat, G., and Sylvan, J. B. (2011). Under the sea: microbial life in volcanic oceanic crust. Nat. Rev. 9, 703-712. doi: 10.1038/nrmicro2647

Ehrhardt, C. J., Haymon, R. M., Lamontagne, M. G., and Holden, P. A. (2007). Evidence for hydrothermal Archaea within the basaltic flanks of the East Pacific Rise. Environ. Microbiol. 9, 900-912. doi: 10.1111/j.1462-2920.2006. 01211.x

Emerson, D., Emily, F., and McBeth, J. (2010). Iron-oxidizing bacteria: an environmental and genomic perspective. Ann. Rev. Microbiol. 64, 561-583. doi: 10.1146/annurev.micro.112408.134208

Emerson, D., and Ghiorse, W. C. (1992). Isolation, cultural maintenance, and taxonomy of a sheath-forming strain of Leptothrix discophora and characterization of manganese-oxidizing activity associated with the sheath. Appl. Envrion. Microbiol. 58, 4001-4010.

Emerson, D., and Moyer, C. L. (2002). Neutrophilic Fe-oxidizing bacteria are abundant at the Loihi Seamount hydrothermal vents and play a major role in $\mathrm{Fe}$ oxide deposition. Appl. Environ. Microbiol. 68, 3085-3093. doi: 10.1128/AEM. 68.6.3085-3093.2002

Engelen, B., Ziegelmüller, K., Wolf, L., Kôpke, B., Gittel, A., and Cypionka, H. (2008). Fluids from the oceanic crust support microbial activities within the deep biosphere. Geomicrobiol. J. 25, 56-66. doi: 10.1080/01490450701829006
Erickson, K. L., Macko, S. A., and Van Dover, C. L. (2009). Evidence for a chemoautotrophically based food web at inactive hydrothermal vents (Manus Basin). Deep Sea Res. Part II 56, 1577-1585. doi: 10.1016/j.dsr2.2009.05.002

Farmer, V. C. (1974). “The layer silicates," in Infrared Spectra of Minerals, ed. V. C. Farmer (London: Mineralogical Society), 331-363. doi: 10.1180/mono-4.15

Fleming, E. J., Davis, R. E., McAllister, S. M., Chan, C. S., Moyer, C. L., Tebo, B. M., et al. (2013). Hidden in plain sight: discovery of sheath-forming, iron-oxidizing Zetaproteobacteria at Loihi Seamount, Hawaii, USA. FEMS Microbiol. Ecol. 85, 116-127. doi: 10.1111/1574-6941.12104

Fortin, D., Ferris, F. G., and Scott, S. D. (1998). Formation of iron-silicates and iron oxides on bacterial surfaces in the samples collected near hydrothermal vents on the Southern Explorer Ridge in the northeast Pacific Ocean. Am. Mineral. 83, 1399-1408. doi: 10.2138/am-1998-11-1229

Frank, D. N. (2009). BARCRAWL and BARTAB: software tools for the design and implementation of barcoded for highly multiplexed DNA sequencing. BMC Bioinformatics 10:362. doi: 10.1186/1471-2105-10-362

Gotić, M., and Musić, S. (2007). Mössbauer, FT-IR and FE SEM investigation of iron oxides precipitated from FeSO4 solutions. J. Mol. Struct. 834, 445-453. doi: 10.1016/j.molstruc.2006.10.059

Guo, H., and Barnard, A. S. (2013). Naturally occurring iron oxide nanoparticles: morphology, surface chemistry and environmental stability. J. Mater. Chem. A 1, 27-42. doi: 10.1039/C2TA00523A

Hannington, M. D. (1993). The formation of atacamite during weathering of sulfides on the modern seafloor. Can. Mineral. 31, 945-956.

Haymon, R. M., White, S. M., Baker, E. T., Anderson, P. G., Macdonald, K. C., and Resing, J. A. (2008). High-resolution surveys along the hot spot - affected Galapagos Spreading Center: 3. Black smoker discoveries and the implications for geological controls on hydrothermal activity. Geochem. Geophys. Geosyst. 9, Q12006. doi: 10.1029/2008GC002114

Herzig, P. M., and Hannington, M. D. (1995). Polymetallic massive sulfides at the modem seafloor. Ore Geol. Rev. 10, 95-115. doi: 10.1016/0169-1368(95)00009-7

Hoek, J., Banta, A., Hubler, F., and Reysenbach, A.-L. (2003). Microbial diversity of a sulphide spire located in the Edmond deep-sea hydrothermal vent filed on the Central Indian Ridge. Geobiology 1, 119-127. doi: 10.1046/j.1472-4669. 2003.00015.x

Huber, J. A., Johnson, H. P., Butterfield, D. A., and Baross, J. A. (2006). Microbial life in ridge flank crustal fluids. Environ. Microbiol. 8, 88-99. doi: 10.1111/j. 1462-2920.2005.00872.x

Huber, T., Faulkner, G., and Hugenholtz, P. (2004). Bellerophon: a program to detect chimeric sequences in multiple sequence alignments. Bioinformatics 20 , 2317-2319. doi: 10.1093/bioinformatics/bth226

Hugoni, M., Domaizon, I., Taib, N. C., Biderre-Petit, H., Agogué, P. E., Galand, D., et al. (2015). Temporal dynamics of active Archaea in oxygen-depleted zones of two deep lakes. Environ. Microbiol. Rep. 7, 321-329. doi: 10.1111/1758-2229. 12251

Jaeschke, A., Eickmann, B., Lang, S. Q., Bernasconi, S. M., Strauss, H., and FruhGreen, G. L. (2014). Biosignatures in chimney structures and sediment from the Loki's Castle low-temperature hydrothermal vent field at the Arctic Mid-Ocean Ridge. Extremophiles 18, 545-560. doi: 10.1007/s00792-014-0640-2

Jaeschke, A., Jorgensen, S. L., Bernasconi, S. M., and Pedersen, R. B. (2012). Microbial diversity of Loki's Castle black smokers at the Arctic Mid-Ocean Ridge. Geobiology 10, 548-561. doi: 10.1111/gbi.12009

Kato, S., Kobayashi, C., Kakegawa, T., and Yamagishi, A. (2009). Microbial communities in iron-silica-rich microbial mats at deep-sea hydrothermal fields of the southern Mariana Trough. Environ. Microbiol. 11, 3210-3222. doi: 10. 1111/j.1462-2920.2009.01930.x

Kato, S., Krepski, S., Chan, C., Itoh, T., and Ohkuma, M. (2014). Ferriphaselus amnicola gen. nov., sp. nov., a neutrophilic, stalk-forming, iron-oxidizing bacterium isolated from an iron-rich groundwater seep. Int. J. Syst. Evol. Microbiol. 64, 921-925. doi: 10.1099/ijs.0.058487-0

Kato, S., Takano, Y., Kakegawa, T., Oba, H., Inoue, K., Kobayashi, C., et al. (2010). Biogeography and biodiversity in sulfide structure of active and inactive vents at deep-sea hydrothermal fields of the Southern Mariana Trough. Appl. Environ. Microbiol. 76, 2968-2979. doi: 10.1128/AEM.00478-10

Kennedy, C. B., Scott, S. D., and Ferris, F. G. (2003). Ultrastructure and potential sub-seafloor evidence of bacteriogenic iron oxides from Axial Volcano, Juan de Fuca Ridge, north-east Pacific Ocean. FEMS Microbiol. Ecol. 43, 247-254. doi: 10.1111/j.1574-6941.2003.tb01064.x 
Koji, N., and Solomon, P. H. (1977). Infrared Adsorption Spectroscopy, 2nd Edn. San Francisco, CA: Holden-Day Inc.

Kormas, K. A., Smith, D. C., Edgcomb, V., and Teske, A. (2003). Molecular analysis of deep subsurface microbial communities in Nankai Trough sediments (ODP Leg 190, Site 1176). FEMS Microbiol. Ecol. 45, 115-125. doi: 10.1016/S01686496(03)00128-4

Kormas, K. A., Tivey, M. K., Von Damm, K., and Teske, A. (2006). Bacterial and archaeal phylotypes associated with distinct mineralogical layers of a white smoker spire from a deep-sea hydrothermal vent site $\left(9^{\circ} \mathrm{N}\right.$, East Pacific Rise). Environ. Microbiol. 8, 909-920. doi: 10.1111/j.1462-2920.2005.0 0978.x

Koski, R. A., Clague, D. A., and Oudin, E. (1984). Mineralogy and chemistry of massive sulfide deposits from the Juan de Fuca Ridge. Geol. Soc. Am. Bull. 95, 930-945. doi: 10.1130/0016-7606(1984)95<930:MACOMS>2.0.CO;2

Krepski, S. T., Emerson, D., Hredzak-Showalter, P. L., Luther, G. W. III., and Chan, C. (2013). Morphology of biogenic iron oxide records microbial physiology and environmental conditions: toward interpreting iron microfossils. Geobiology 11, 457-471. doi: 10.1111/gbi.12043

Kuever, J., Rainey, F. A., and Widdel, F. (2015). “Desulfobulbus," in Bergey's Manual of Systematics of Archaea and Bacteria, 2nd Edn, Vol. 2, eds G. M. Garrity, D. J. Brenner, N. R. Krieg, and J. T. Staley (New York, NY: Springer), 1-6.

Lane, D. J. (1991). "16S/23S rRNA sequencing," in Nucleic Acid Techniques in Bacterial Systematics, eds E. Stackebrandt and M. Goodfellow (New York, NY: John Wiley and Sons Publishing Inc.), 115-176.

Larkin, M. A., Blackshields, G., Brown, N. P., Chenna, R., McGettigan, P. A., McWilliam, H., et al. (2007). Clustal W and Clustal X version 2.0. Bioinformatics 23, 2947-2948. doi: 10.1093/bioinformatics/btm404

Li, J., Zhou, H., Fang, J., Sun, Y., and Dasgupta, S. (2014). Microbial distribution in different spatial positions within the walls of a black sulfide chimney. Mar. Ecol. Prog. Ser. 508, 67-85. doi: 10.3354/meps10841

Li, J., Zhou, H., Peng, X., Wu, Z., Chen, S., and Fang, J. (2012). Microbial diversity and biomineralization in low-temperature hydrothermal iron-silicarich precipitates of the Lau Basin hydrothermal field. FEMS Microbiol. Ecol. 81, 205-216. doi: 10.1111/j.1574-6941.2012.01367.x

López-García, P., Philippe, H., Gail, F., and Moreira, D. (2003). Autochthonous eukaryotic diversity in hydrothermal sediment and experimental microcolonizers at the Mid-Atlantic Ridge. Proc. Natl. Acad. Sci. U.S.A. 100, 697-702. doi: 10.1073/pnas.0235779100

Maginn, E. J., Little, C. T. S., Herrington, R. J., and Mills, R. A. (2002). Sulphide mineralisation in the deep sea hydrothermal vent polychaete, Alvinella pompejana: implications for fossil preservation. Mar. Geol. 181, 337-356. doi: 10.1111/gbi.12123

McAllister, S. M., Davis, R. E., McBeth, J. M., Tebo, B. M., Emerson, D., and Moyer, C. L. (2011). Biodiversity and emerging biogeography of the neutrophilic ironoxidizing Zetaproteobacteria. Appl. Environ. Microbiol. 77, 5445-5457. doi: 10. 1128/AEM.00533-11

McBeth, J. M., Little, B. J., Ray, R. I., Farrar, K. M., and Emerson, D. (2011). Neutrophilic iron-oxidizing "Zetaproteobacteria" and mild steel corrosion in nearshore marine and estuarine environments. Appl. Environ. Microbiol. 77, 1405-1412. doi: 10.1128/AEM.02095-10

McCollom, T. M. (2000). Geochemical constraints on primary productivity in submarine hydrothermal vent plumes. Deep Sea Res. Part I 47, 85-101. doi: 10.1016/S0967-0637(99)00048-5

Meyer, J. L., Akerman, N. A., Proskurowski, G., and Huber, J. (2013). Microbiological characterization of post-eruption snowblower vents at Axial Seamount, Juan de Fuca Ridge. Front. Microbiol. 4:153. doi: 10.3389/fmicb. 2013.00153

Nercessian, O., Reysenbach, A.-L., Prieur, D., and Jeanthon, C. (2003). Archaeal diversity associated with in situ samplers deployed on hydrothermal vents on the East Pacific Rise (13N). Environ. Microbiol. 5, 492-502. doi: 10.1046/j.14622920.2003.00437.x

Orcutt, B. N., Bach, W., Becker, K., Fisher, A. T., Hentscher, M., Toner, B. M., et al. (2011). Colonization of subsurface microbial observation deployed in young ocean crust. ISME J. 5, 692-703. doi: 10.1038/ismej.20 10.157

Page, A., Tivey, M. K., Stakes, D. S., and Reysenbach, A.-L. (2008). Temporal and spatial archaeal colonization of hydrothermal vent deposits. Environ. Microbiol. 10, 874-884. doi: 10.1111/j.1462-2920.2007.01505.x
Peng, X., Zhou, H., Yao, H., Li, J., and Wu, Z. (2009). Ultrastructural evidence for iron accumulation within the tube of Vestimentiferan Ridgeia piscesae. Biometals 22, 723-732. doi: 10.1007/s10534-009-9216-5

Perfit, M. R., Cann, J. R., Fornari, D. J., Engels, J., Smith, D. K., Ridley, W. I., et al. (2003). Interaction of sea water and lava during submarine eruptions at mid-ocean ridges. Nature 426, 62-65. doi: 10.1038/nature02032

Pham, V. D., Konstantinidis, K. T., Palden, T., and DeLong, E. F. (2008). Phylogenetic analyses of ribosomal DNA-containing bacterioplankton genome fragments from a 4000m vertical profile in the North Pacific Subtropical Gyre. Environ. Microbiol. 10, 2313-2330. doi: 10.1111/j.1462-2920.2008.01657.x

Pichler, T., Ian Ridley, W., and Nelson, E. (1999). Low-temperature alteration of dredged volcanics from the Southern Chile Ridge: additional information about early stages of seafloor weathering. Mar. Geol. 159, 155-177. doi: 10.1016/ S0025-3227(99)00008-0

Polz, M. F., and Cavanaugh, C. M. (1995). Dominance of one bacterial phylotype at a Mid-Atlantic Ridge hydrothermal vent site. Proc. Natl. Acad. Sci. U.S.A. 92, 7232-7236. doi: 10.1073/pnas.92.16.7232

Reeves, E. P., Yoshinaga, M. Y., Pjevac, P., Goldenstein, N. I., Peplies, J., Meyerdierks, A., et al. (2014). Microbial lipids reveal carbon assimilation patterns on hydrothermal sulfide chimneys. Environ. Microbiol. 16, 3515-3532. doi: 10.1111/1462-2920.12525

Reysenbach, A.-L., Liu, Y. T., Banta, A. B., and Beveridge, T. J. (2006). Isolation of a ubiquitous obligate thermoacidophilic archaeon from deep-sea hydrothermal vents. Nature 442, 444-447. doi: 10.1038/nature04921

Reysenbach, A.-L., Longnecher, K., and Kirshtein, J. (2000). Novel bacterial and archaeal lineages from an In Situ growth chamber deployed at a Mid-Atlantic Ridge hydrothermal vent. Appl. Environ. Microbiol. 66, 3798-3806. doi: 10. 1128/AEM.66.9.3798-3806.2000

Rogers, D. R., Santelli, C. M., and Edwards, K. J. (2003). Geomicrobiology of deepsea deposits: estimating community diversity from low-temperature seafloor rocks and minerals. Geobiology 1, 109-117. doi: 10.1046/j.1472-4669.2003. 00009.x

Ryskin, Y. I. (1974). "The vibration of protons in minerals: hydroxyl, water and ammonium," in The Infrared Spectra of Minerals Monograph, ed. V. C. Farmer (London: Mineralogical Society), 137-181. doi: 10.1180/mono-4.9

Schloss, P. D., and Handelsman, J. (2005). Introducing DOTUR, a computer program for defining operational taxonomic units and estimating species richness. Appl. Environ. Microbiol. 71, 1501-1506. doi: 10.1128/AEM.71.3. 1501-1506.2005

Schoeffield, A. J., and Williams, H. N. (1990). Efficiencies of recovery of bdellovibrios from brackish water environments by using various bacterial species as prey. Appl. Environ. Microbiol. 56, 230-236.

Schrenk, M. O., Kelley, D. S., Delaney, J. R., and Baross, J. A. (2003). Incidence and diversity of microorganisms within the walls of an active deep-sea sulfide chimney. Appl. Environ. Microbiol. 69, 3580-3592. doi: 10.1128/AEM.69.6. 3580-3592.2003

Suzuki, Y., Inagaki, F., Takai, K., Nealson, K. H., and Horikoshi, K. (2004). Microbial diversity in inactive chimney structures from deep-sea hydrothermal systems. Microb. Ecol. 47, 186-196. doi: 10.1007/s00248-003-1014-y

Sylvan, J. B., Sia, T. Y., Haddad, A. G., Briscoe, L. J., Toner, B. M., Girguis, P. R., et al. (2013). Low temperature geomicrobiology follows host rock composition along a geochemical gradient in Lau Basin. Front. Microbiol. 4:61. doi: 10.3389/ fmicb.2013.00061

Sylvan, J. B., Toner, B. M., and Edwards, K. J. (2012). Life and death of deep-sea vents: bacterial diversity and ecosystem succession on inactive hydrothermal sulfides. mBio 3:e0279-11. doi: 10.1128/mBio.00279-11

Takai, K., and Horikoshi, K. (1999). Genetic diversity of archaea in deep-sea hydrothermal vent environments. Genetics 152, 1285-1297.

Takai, K., and Sako, Y. (1999). A molecular view of archaeal diversity in marine and terrestrial hot water environments. FEMS Microbiol. Ecol. 28, 177-188. doi: 10.1111/j.1574-6941.1999.tb00573.x

Tamura, K., Peterson, D., Peterson, N., Stecher, G., Nei, M., and Kumar, S. (2011). MEGA5: molecular evolutionary genetics analysis using maximum likelihood, evolutionary distance, and maximum parsimony methods. Mol. Biol. Evol. 28, 2731-2739. doi: 10.1093/molbev/msr121

Teske, A., and Sørensen, K. B. (2008). Uncultured archaea in deep marine subsurface sediments: have we caught them all? ISME J. 2, 3-18. doi: 10.1038/ ismej. 2007.90 
Tivey, M. K. (1995). "Modeling chimney growth and associated fluid flow at seafloor hydrothermal vent sites," in Seafloor Hydrothermal Systems - Physical, Chemical, Biological, and Geological Interactions, eds S. E. Humphris, R. A. Zierenberg, L. S. Mullineaux, and R. E. Thompson (Washington, DC: American Geophysical Union), 158-177.

Toner, B. M., Lesniewski, R. A., Marlow, J. J., Briscoe, L. J., Santelli, C. M., Bach, W., et al. (2013). Mineralogy drives bacterial biogeography of hydrothermally inactive seafloor sulfide deposits. Geomicrobiol. J. 30, 313-326. doi: 10.1080/ 01490451.2012.688925

Toner, B. M., Rouxel, O. J., Santelli, C. M., Bach, W., and Edwards, K. J. (2016). Iron transformation pathways and redox micro-environments in seafloor sulfidemineral deposits: spatially resolved Fe XAS and $857 / 54 \mathrm{Fe}$ observations. Front. Microbiol. 7:648. doi: 10.3389/fmicb.2016.00648

Tuysuz, H., Salabas, E. L., Weidenthaler, C., and Schuth, F. (2008). Synthesis and magnetic investigation of ordered mesoporous two-line ferrihydrite. J. Am. Chem. Soc. 130, 280-287. doi: 10.1021/ja075528j

Vempati, R. K., Loeppert, R. H., Sittertz-Bhatkar, H., and Burghardt, R. C. (1990). Infrared vibrations of hematite formed from aqueous- and drythermal incubation of Si-containing ferrihydrite. Clays Clay Miner. 38, 294-298. doi: 10.1346/CCMN.1990.0380308

Wang, F., Zhou, H., Meng, J., Peng, X., Jiang, L., Sun, P., et al. (2009). GeoChipbased analysis of metabolic diversity of microbial communities at the Juan de Fuca Ridge hydrothermal vent. Proc. Natl. Acad. Sci. U.S.A. 106, 4840-4845. doi: 10.1073/pnas.0810418106

Wang, J., Muyzer, G., Bodelier, P., and Laanbroek, H. J. (2009). Diversity of iron oxidizers in wetland soils revealed by novel 16S rRNA primers targeting Gallionella-related bacteria. ISME J. 3, 715-725. doi: 10.1038/ismej. 2009.7

Welsh, R. M., Zaneveld, J. R., Rosales, S. M., Payet, J. P., Burkephile, D. E., and Thurber, R. V. (2015). Bacterial predation in a marine host-associated microbiome. ISME J. 10, 1540-1544. doi: 10.1038/ismej.2015.219
Wirsen, C. O., Jannasch, H. W., and Molyneaux, S. J. (1993). Chemosynthetic microbial activity at Mid-Atlantic Ridge hydrothermal vent sites. J. Geophys. Res. 98, 9693-9703. doi: 10.1029/92JB01556

Yilmaz, P., Iversen, M. H., Hankeln, W., Kottman, R., Quast, C., and Glöckner, F. O. (2012). Ecological structuring of bacterial and archaeal taxa in surface ocean waters. FEMS Microbiol. Ecol. 81, 373-385. doi: 10.1111/j.1574-6941. 2012.01357.x

Yilmaz, P., Yarza, P., Rapp, J. Z., and Glockner, F. O. (2016). Expanding the world of marine bacterial and archaeal clades. Front. Microbiol. 6:1524. doi: 10.3389/ fmicb.2015.01524

Zhang, X., Chen, Y., Zhao, N., Liu, H., and Wei, Y. (2014). Citrate modified ferrihydrite microstructures: facile synthesis, strong adsorption and excellent Fenton-like catalytic properties. RSC Adv. 4, 21575-21583. doi: 10.1039/ C4RA00978A

Zhou, H., Li, J., Peng, X., Meng, J., Wang, F., and Ai, Y. (2009). Microbial diversity of a sulfide black smoker in Main Endeavour hydrothermal vent field, Juan de Fuca Ridge. J. Microbiol. 47, 235-247. doi: 10.1007/s12275-008-0311-z

Zhou, J., Bruns, M., and Tiedje, J. (1996). DNA recovery from soils of diverse composition. Appl. Environ. Microbiol. 62, 316-322.

Conflict of Interest Statement: The authors declare that the research was conducted in the absence of any commercial or financial relationships that could be construed as a potential conflict of interest.

Copyright (c) 2017 Li, Cui, Yang, Cui, Wei, Wu, Wang and Zhou. This is an openaccess article distributed under the terms of the Creative Commons Attribution License (CC BY). The use, distribution or reproduction in other forums is permitted, provided the original author(s) or licensor are credited and that the original publication in this journal is cited, in accordance with accepted academic practice. No use, distribution or reproduction is permitted which does not comply with these terms. 